\title{
Differential signature of the centrosomal MARK4 isoforms in glioma
}

Ivana Magnani ${ }^{\mathrm{a}}$, Chiara Novielli ${ }^{\mathrm{a}}$, Laura Fontana $^{\mathrm{a}}$, Silvia Tabano ${ }^{\mathrm{a}}$, Davide Rovina ${ }^{\mathrm{a}}$, Ramona F. Moroni ${ }^{\mathrm{b}}$, Dario Bauer ${ }^{\mathrm{c}}$, Stefania Mazzoleni ${ }^{\mathrm{d}}$, Elisa A. Colombo ${ }^{\mathrm{a}}$, Gabriella Tedeschi ${ }^{\mathrm{e}}$, Laura Monti ${ }^{\mathrm{a}}$, Giovanni Porta ${ }^{\mathrm{f}}$, Silvano Bosari ${ }^{\mathrm{c}}$, Carolina Frassoni ${ }^{\mathrm{b}}$, Rossella Galli ${ }^{\mathrm{d}}$, Lorenzo Bello ${ }^{\mathrm{g}}$ and Lidia Larizza ${ }^{\mathrm{a}, *}$

${ }^{a}$ Department of Medicine, Surgery and Dentistry, Ospedale San Paolo, Medical Genetics, Università degli studi di Milano, Milan, Italy

${ }^{\mathrm{b}}$ Unit of Clinical Epileptology and Experimental Neurophysiology, Fondazione I.R.C.C.S. Istituto Neurologico "C. Besta”, Milan, Italy

${ }^{\mathrm{c}}$ Department of Medicine, Surgery and Dentistry, Pathology Unit, Ospedale San Paolo, Università degli studi di Milano, and Fondazione IRCCS Ca' Granda, Pathology Unit, Ospedale Maggiore Policlinico, Milan, Italy

${ }^{\mathrm{d}}$ Neural Stem Cell Biology Unit, Division of Regenerative Medicine, Stem Cells and Gene Therapy, San Raffaele Scientific Institute, Milan, Italy

${ }^{\mathrm{e}}$ Department of Animal Pathology, Hygiene and Veterinary Public Health, Università degli Studi di Milano and Fondazione Filarete, Milan, Italy

${ }^{\mathrm{f}}$ Department of Experimental and Clinical Biomedical Sciences, Università dell'Insubria, Varese, Italy

${ }^{\mathrm{g}}$ Department of Neurological Science, Fondazione IRCCS Ospedale Maggiore Policlinico, Università degli studi di Milano, and Istituto Clinico Humanitas, Milan, Italy

Received: June 1, 2011

Accepted: September 11, 2011

\begin{abstract}
Background: MAP/microtubule affinity-regulating kinase 4 (MARK4) is a serine-threonine kinase expressed in two spliced isoforms, MARK4L and MARK4S, of which MARK4L is a candidate for a role in neoplastic transformation.

Methods: We performed mutation analysis to identify sequence alterations possibly affecting MARK4 expression. We then investigated the MARK4L and MARK4S expression profile in 21 glioma cell lines and 36 tissues of different malignancy grades, glioblastoma-derived cancer stem cells (GBM CSCs) and mouse neural stem cells (NSCs) by real-time PCR, immunoblotting and immunohistochemistry. We also analyzed the sub-cellular localisation of MARK4 isoforms in glioma and normal cell lines by immunofluorescence.

Results: Mutation analysis rules out sequence variations as the cause of the altered MARK4 expression in glioma. Expression profiling confirms that MARK4L is the predominant isoform, whereas MARK4S levels are significantly decreased in comparison and show an inverse correlation with tumour grade. A high MARK4L/MARK4S ratio also characterizes undifferentiated cells, such as GBM CSCs and NSCs. Accordingly, only MARK4L is expressed in brain neurogenic regions. Moreover, while both MARK4 isoforms are localised to the centrosome and midbody in glioma and normal cells, the L isoform exhibits an additional nucleolar localisation in tumour cells.

Conclusions: The observed switch towards MARK4L suggests that the balance between the MARK4 isoforms is carefully guarded during neural differentiation but may be subverted in gliomagenesis. Moreover, the MARK4L nucleolar localisation in tumour cells features this MARK4 isoform as a nucleolus-associated tumour marker.
\end{abstract}

Keywords: MARK4 kinase, glioma, alternative splicing, neural/cancer stem cells, nucleolus

\footnotetext{
${ }^{*}$ Corresponding author: Lidia Larizza, Dipartimento di Medicina, Chirurgia e Odontoiatria, Sezione di Genetica Medica, Università di Milano, Polo San Paolo, via di Rudinì, 8, 20142 Milan, Italy. Tel.: +39 02 50323206; Fax: +39 02 50323026; E-mail: lidia.larizza@unimi.it.
} 


\section{Introduction}

The MAP/microtubule affinity-regulating kinase (MARK) proteins, a family of serine-threonine kinases related to PAR-1 (partitioning-defective 1) [1, 2], first became known for their ability to phosphorylate microtubule-associated proteins (MAPs), leading to the destabilization of microtubules [3, 4]. Among the wide range of functions ascribed to MARKs, roles in cell polarity, cell cycle control and cell signalling have been frequently examined [3-8]. All members of the MARK family (MARK1-4) [9] share a nearly identical protein structure, which includes the kinaseassociated domain 1 (KA1) or a similar domain at the $\mathrm{C}$ terminus, and are regulated by multiple pathways acting through different mechanisms [10]. The function of the KA1 domain is still unknown, but an autoinhibitory function and/or interaction with proteins binding to the tail region have been shown in Saccharomyces and proposed as novel strategies for the regulation of MARKs and related kinases [7]. The MARK4 human paralogue encodes two splice variants, namely $\mathrm{L}$ and $\mathrm{S}$. The alternative splicing of exon 16, which causes a frameshift and creates a downstream stop codon, accounts for the difference between the carboxy-terminal ends of MARK4L and S. MARK4L contains the KA1 motif, whereas MARK4S has a unique domain with no homology with any known protein structure [11,12], suggesting that the two isoforms have different functions. In keeping with this notion, the two MARK4 isoforms have been reported to have different expression patterns. MARK4S was found to be up-regulated in mouse neurons after induced focal ischemia [13], and it appeared to be predominantly expressed in normal brain tissue and in mature and differentiated neurons [12]. Conversely, MARK4L was up-regulated in hepatocarcinoma cell lines [11] and highly expressed in primary glioma cell lines and neural progenitor cells, suggesting involvement in cellular proliferation [14]. This also applies to MARK3, which has been found mutated in two colorectal tumours [15], and $M A R K 1$, which is down-regulated in primary gastric cancers [16] and up-regulated in lung carcinoma [17]. By using a full chromosome 19 coverage array, we have shown that MARK4 gene is not amplified in glioma [18], although it resides within a region of gain at the centromeric boundary of the 19q13.3 $\mathrm{LOH}$ area. These findings suggest that MARK4L upregulation in glioma is caused by mechanisms other than copy number alterations. In contrast to MARK1,
MARK2 and MARK3, which exhibit uniform cytoplasmic localisation, exogenous MARK4 associates with microtubules, centrosomes, and neurite-like processes of neuroblastoma cell lines, attesting to its involvement in microtubule organization in neuronal cells [4]. We recently investigated the subcellular localisation of the endogenous MARK4L isoform in glioma and showed that it displays multiple localisations, being found in centrosomes at all mitotic stages, midbodies, nucleoli and their respective biochemical fractions [19]. The localisation pattern of MARK4L emerging from the above studies provides further evidence for MARK4L influence on microtubules, particularly those affecting the centrosome and midbody.

The present study is aimed at deepening understanding of the potential oncogenic role of MARK4 in human glioma, the most common brain tumour in adults. We first excluded the possibility that sequence changes within the MARK4 gene, including those at the alternative splice sites leading to the $\mathrm{L}$ isoform, could be related to the reported up-regulation. We then traced MARK4L and MARK4S expression profile in glioma cell lines and tissues with different malignancy grades and in glioblastoma-derived cancer stem cells (GBM CSCs) by real-time PCR, immunoblotting (IB) and immunohistochemistry (IHC). We also performed in vivo localisation studies of MARK4S and MARK4L in mouse and human adult and embryonic brain. Finally, we investigated and compared the subcellular localisations of MARK4 splice variants in glioma cell lines and in normal cells. The integration of these datasets highlighted a differential signature of the two MARK4 isoforms supporting a distinct role in the pathogenesis of gliomas.

\section{Materials and methods}

\subsection{Cell cultures}

Primary glioma cell lines (Table 1A), obtained from post-surgery specimens divided in non GBM (1 pylocitic astrocytoma, 1 oligoastrocytoma, and 7 anaplastic astrocytomas) and GBM (10 glioblastomas and 2 giant cell glioblastomas), as well as the spheroid NHNPCs (Normal Human Neural Progenitor Cells; Lonza, Walkersville, MD, USA) were grown as described elsewhere $[14,20,21]$. The human neural progenitor cell line ReNcellCX (Millipore, 
Table 1A

Set of 21 investigated primary glioma cell lines

\begin{tabular}{|c|c|c|}
\hline Cell line & Sex/Age at surgery & WHO diagnosis/grade \\
\hline G-91 & $\mathrm{M} / 4$ & $\mathrm{PA} / \mathrm{I}$ \\
\hline G-157 & $\mathrm{M} / 31$ & $\mathrm{OA} / \mathrm{II}$ \\
\hline G-110 & n.a. & AA/III \\
\hline G-114 & $\mathrm{F} / 10$ & AA/III \\
\hline G-141 & n.a. & AA/III \\
\hline G-151 & n.a. & AA/III \\
\hline G-6 & n.a. & AA/III \\
\hline MI-29 & $\mathrm{F} / 6$ & AA/III \\
\hline G-47 & n.a. & AA/III \\
\hline MI-4 & $\mathrm{F} / 52$ & GBM/IV \\
\hline G-32 & $\mathrm{M} / 63$ & GBM/IV \\
\hline MI-38 & $\mathrm{F} / 73$ & GBM/IV \\
\hline MI-45 & n.a. & GBM/IV \\
\hline MI-51 & n.a. & GBM/IV \\
\hline MI-60 & $F / 36$ & GBM/IV \\
\hline MI-63 & $\mathrm{M} / 45$ & GBM/IV \\
\hline MI-70 & $\mathrm{F} / 66$ & GBM/IV \\
\hline G-150 & n.a. & GBM/IV \\
\hline GBM & $\mathrm{M} / 48$ & GBM/IV \\
\hline G-1 & $\mathrm{F} / 62$ & GBM/IV \\
\hline MI-7 & $\mathrm{M} / 51$ & giant cell GBM/IV \\
\hline
\end{tabular}

Glioma cell lines are grouped in non GBM (PA, OA, AA) and GBM (GBM, giant cell GBM). Abbreviations: M, male; F, female; PA, pilocytic astrocytoma; OA, oligoastrocytoma; AA, anaplastic astrocytoma; GBM, glioblastoma; n.a., not available.

Billerica, MA, USA) was grown as a monolayer on laminin (Sigma, Saint Louis, MI, USA) diluted with DMEM/F12 medium (Millipore) to $20 \mu \mathrm{g} / \mathrm{ml}$ and was maintained by serial passages in a defined serum-free medium (Millipore/Chemicon) containing $20 \mathrm{ng} / \mathrm{ml}$ epidermal growth factor (EGF) (Sigma) and $20 \mathrm{ng} / \mathrm{ml}$ fibroblast growth factor-2 (FGF-2) (Invitrogen, Camarillo, CA, USA) at $37^{\circ} \mathrm{C}$ in $5 \% \mathrm{CO}_{2}$. Human adult skin fibroblasts (grown in RPMI $1640+10 \%$ foetal calf serum (FBS) $+1 \%$ penicillin-streptomycin) and human adult myoblasts (grown in DMEM $+20 \%$ FBS $+1 \%$ penicillin-streptomycin $+2 \mathrm{mM}$ L-glutamine $+10 \mu \mathrm{g} / \mathrm{ml}$ insulin $+25 \mathrm{ng} / \mathrm{ml} \mathrm{FGF}-2+10 \mathrm{ng} / \mathrm{ml}$ EGF) were incubated in $5 \% \mathrm{CO}_{2}$ at $37^{\circ} \mathrm{C}$.

Human GBM CSCs and mouse neural stem cells (NSCs) were obtained from post-surgery specimens of primary GBM and from the sub-ventricular zone of post-natal 7-day-old C57 mice, respectively. GBM CSCs were obtained through enzymatic digestion of tumour tissues, followed by culture of the cell suspension in DMEM/F12 medium without serum and in the presence of EGF $(20 \mathrm{ng} / \mathrm{ml})$ and FGF-2 $(10 \mathrm{ng} / \mathrm{ml})$. GBM CSCs were characterized for self-renewal, multipotency and tumourigenicity as described [22]. Mouse
NSCs were obtained and characterized according to the protocol described by Foroni et al. [23].

A few GBM CSCs and NSCs were also terminally differentiated into the three major neural cell types by culturing them in mitogen-free medium supplemented with $2 \%$ FBS. Immunofluorescence for neural antigens was performed to assess differentiation [23].

\subsection{Tissue samples}

A total of 36 human glioma post-surgery specimens (16 oligodendrogliomas, O; 7 astrocytomas, A; and 13 glioblastomas, GBM; Table 1B) were obtained, in accordance with a protocol approved by the Institutional Review Board of the University of Milan's Neurosurgery Department, from patients with no previous chemotherapy or radiation treatment.

Human normal brain (HNB) samples included: (1) autopsies of three stillborn infants who died after premature delivery during the 23 rd-27th gestational week; death was not due to neurological disorders or brain malformations, as detected by macroscopic and microscopic examination; according to the Italian law, autopsies were performed 24 hours after death; and (2) brain specimens from two drug-resistant patients operated on for intractable epilepsy; the surgery was performed for strictly therapeutic reasons after the patients had given their informed consent; during the neuropathological investigation, samples did not show any cytological alteration.

Normal rodent brain tissues were obtained from three adult mice (C57B6/CD1), two adult rats (CD1) and one rat embryo at embryonic day (E) 15 from Charles River Laboratories (Calco, Italy). Animals were brought up and treated in accordance with the European Communities Council Directive (86/609/EEC).

\subsection{DNA extraction and mutation analysis}

Total DNA was extracted from cell lines using the QIAmp DNA mini kit (Qiagen, Milano, Italy) and from tissue samples using TRI reagent (Total RNA Isolation reagent; Sigma) according to the manufacturers' protocols. Approximately $60 \mathrm{ng}$ were amplified by PCR using GoTaq polymerase (Promega, Madison, WI, USA) and MARK4 specific primers. PCR products were sequenced using the Big Dye Terminator v.3.1 Cycle Sequencing Kit and the ABI PRISM 3130 
Table 1B

Set of 36 investigated glioma biopsies: molecular and clinical characterization

\begin{tabular}{|c|c|c|c|c|c|c|c|c|}
\hline Sample & Sex/Age & WHO diagnosis/grade & Tumor site & SVZ & Survival/Recurrence & ${ }^{\mathrm{m}} \mathrm{MGMT}$ & $1 \mathrm{p}$ del & $19 q$ del \\
\hline 4 & $\mathrm{~F} / 52$ & $\mathrm{O} / \mathrm{II}$ & n.a. & n.a. & n.a. & + & + & + \\
\hline 6 & $\mathrm{M} / 54$ & $\mathrm{O} / \mathrm{II}$ & lt & - & alive/- & - & - & - \\
\hline 42 & $\mathrm{M} / 49$ & $\mathrm{O} / \mathrm{II}$ & $\mathrm{rf}$ & - & alive/+ & n.e. & + & + \\
\hline 71 & $\mathrm{M} / 59$ & $\mathrm{O} / \mathrm{II}$ & $\mathrm{rt}$ & - & alive/- & + & - & - \\
\hline 98 & $\mathrm{M} / 29$ & $\mathrm{O} / \mathrm{II}$ & $\mathrm{rp}$ & - & alive/- & + & + & + \\
\hline 106 & $\mathrm{M} / 38$ & $\mathrm{O} / \mathrm{II}$ & $\mathrm{rf}$ & - & alive/+ & + & + & + \\
\hline 107 & $\mathrm{~F} / 41$ & $\mathrm{O} / \mathrm{II}$ & If & - & alive/+ & + & + & + \\
\hline 112 & $\mathrm{M} / 36$ & $\mathrm{O} / \mathrm{II}$ & $\mathrm{rp}$ & + & alive/- & + & + & + \\
\hline 118 & $\mathrm{M} / 50$ & $\mathrm{O} / \mathrm{II}$ & If & + & alive/- & + & + & + \\
\hline 186 & $\mathrm{~F} / 39$ & $\mathrm{O} / \mathrm{II}$ & $\mathrm{rt}$ & - & alive/- & + & + & + \\
\hline 190 & M/68 & $\mathrm{O} / \mathrm{II}$ & If & + & alive/- & + & + & + \\
\hline 193 & $\mathrm{M} / 45$ & $\mathrm{O} / \mathrm{II}$ & $\mathrm{rf}$ & + & alive/- & + & + & + \\
\hline 196 & $\mathrm{M} / 31$ & $\mathrm{O} / \mathrm{II}$ & rp & - & alive/- & - & - & - \\
\hline 200 & $\mathrm{~F} / 44$ & $\mathrm{O} / \mathrm{II}$ & lt & - & alive/- & + & + & + \\
\hline 217 & $\mathrm{M} / 40$ & $\mathrm{O} / \mathrm{II}$ & lp & - & alive/- & + & + & + \\
\hline 219 & $\mathrm{M} / 46$ & $\mathrm{O} / \mathrm{II}$ & $\mathrm{rf}$ & - & alive/- & + & + & + \\
\hline 1 & $\mathrm{M} / 32$ & $\mathrm{PA} / \mathrm{II}$ & lp & - & alive/- & + & - & - \\
\hline 41 & n.a. & $\mathrm{A} / \mathrm{II}$ & n.a. & n.a. & n.a. & n.e. & n.e. & n.e. \\
\hline 64 & $\mathrm{M} / 34$ & $\mathrm{PA} / \mathrm{II}$ & lf & n.a. & alive/+ & n.e. & n.e. & n.e. \\
\hline 94 & n.a. & $\mathrm{A} / \mathrm{II}$ & n.a. & n.a. & n.a. & n.e. & n.e. & n.e. \\
\hline 108 & $\mathrm{~F} / 52$ & AA/III & lt & - & 32 months & + & - & - \\
\hline 164 & $\mathrm{~F} / 35$ & FA/II & lt & - & alive/- & - & - & - \\
\hline 216 & $\mathrm{M} / 34$ & $\mathrm{PA} / \mathrm{II}$ & lt & n.a. & alive/+ & + & - & - \\
\hline 5 & $\mathrm{~F} / 40$ & GBM/IV & If & + & 34 months & - & + & + \\
\hline 21 & $\mathrm{~F} / 72$ & giant cell GBM/IV & $\mathrm{f}$ & + & 5 months & n.e. & n.e. & n.e. \\
\hline 81 & $\mathrm{~F} / 65$ & GBM/IV & $\mathrm{f}$ & + & 11 months & + & + & + \\
\hline 96 & $\mathrm{M} / 68$ & GBM/IV & f & - & 18 months & + & n.e. & n.e. \\
\hline 100 & $\mathrm{~F} / 66$ & GBM/IV & $\mathrm{f}$ & - & 12 months & + & + & + \\
\hline 113 & $\mathrm{M} / 63$ & GBM/IV & n.a. & n.a. & 15 months & + & - & - \\
\hline 117 & $\mathrm{M} / 70$ & GBM/IV & n.a. & n.a. & 16 months & + & - & - \\
\hline 121 & $\mathrm{M} / 44$ & GBM/IV & lt & + & 3 months & + & - & - \\
\hline 132 & $\mathrm{M} / 51$ & GBM/IV & lt & + & 26 months & - & - & + \\
\hline 144 & $\mathrm{~F} / 56$ & GBM/IV & n.a. & n.a. & 5 months & - & - & - \\
\hline 194 & $\mathrm{M} / 57$ & GBM/IV & $\mathrm{rt}$ & + & alive/- & - & + & - \\
\hline 207 & $\mathrm{M} / 64$ & small cell GBM/IV & n.a. & n.a. & alive/+ & - & - & + \\
\hline 218 & $\mathrm{M} / 58$ & GBM/IV & $\mathrm{rt}$ & + & 14 months & - & + & + \\
\hline
\end{tabular}

Abbreviations: M, male; F, female; O, oligodendroglioma; PA, pilocytic astrocytoma; A, astrocytoma; AA, anaplastic astrocytoma; FA, fibrillary astrocytoma; GBM, glioblastoma; f, frontal; lf, left frontal; lp, left parietal; lt, left temporal; rf, right frontal; rp, right parietal; rt, right temporal; $\mathrm{SVZ}+$, tumor closeness to the sub-ventricular zone; ${ }^{\mathrm{m}} \mathrm{MGMT}, \mathrm{O}^{6}$-methylguanine-DNA methyltransferase methylation; n.a., not available; n.e., not evaluated.

automatic sequencer (both from Applied Biosystems, Foster City, CA, USA). Electropherograms were analysed with ChromasPro software 1.42 (Technelysium Pty Ltd, Tewantin QLD, Australia).

\subsection{RNA isolation, reverse transcription-PCR and real-time PCR}

Total RNA was isolated from cell lines and tissues using TRI reagent and treated with DNase I (RNasefree, New England Bio-Labs, Inc., Ipswich, MA, USA). RNA from total HNB (MVP Total RNA) was also purchased from Stratagene (La Jolla, CA, USA). cDNA was synthesized from 500 or $250 \mathrm{ng}$ of total RNA for cell lines and tissue samples, respectively, using the High Capacity cDNA Reverse Transcription Kit (Applied Biosystems) with random examers. All samples were reverse transcribed in two independent experiments.

The relative mRNA levels of MARK4L and MARK4S were determined by real-time PCR using the StepOne Real-Time PCR System (Applied Biosystems). Isoform-specific TaqMan assays were purchased from Applied Biosystems and used, fol- 
lowing validation, according to the manufacturer's instructions. Different endogenous normalizing genes were used, according to assay efficiency and stability experiments previously performed: GAPDH (assay ID: 4333764F), $\beta$-actin (assay ID: Hs99999903_m1) and $18 \mathrm{~S}$ rRNA (assay ID: Hs99999901_s1). Relative gene expression was determined using the $\Delta \Delta \mathrm{Ct}$ method [24] or the $\Delta \mathrm{Ct}$ method [25].

\subsection{Antibodies}

Polyclonal primary antibodies for MARK4L (rabbit anti-MARK4L; GenScript Corporation, Piscataway, NJ, USA) and MARK4S (goat anti-MARK4S, ab5262; Abcam, Cambridge, UK) were used. The specificity of these antibodies was demonstrated by immunoblotting against the over-expressed MARK4L protein and by mass spectrometry, respectively (Supplementary Information).

For the immunoblotting experiments anti-MARK4L $1: 5.000$, anti-MARK4S $1: 1.250$ and mouse antiGAPDH $1: 10.000$ (ab8245; Abcam) primary antibodies were used. They were detected with horseradish peroxidase (HRP)-conjugated secondary antibodies: goat anti-rabbit IgG $1: 10.000$ (sc-2004), donkey antigoat IgG $1: 25.000$ (sc-2020) and goat anti-mouse IgG $1: 10.000$ (sc-2005) (all from Santa Cruz Biotechnology, Santa Cruz, CA, USA).

For the immunofluorescence experiments, antiMARK4L 1:100, anti-MARK4S 1:200, mouse anti- $\gamma$-tubulin 1:200 (clone GTU-88; Sigma), antinucleolin 1 : 100 (C23 D-6; Santa Cruz Biotechnology) and anti-nucleophosmin $1: 200$ (B23, clone FC82291; Sigma) antibodies were used. The immunofluorescence signals were visualised using different secondary antibodies: goat anti-rabbit $\mathrm{IgG}$ conjugated to fluorescein isothiocyanate (FITC) 1:200 (Sigma), goat anti-mouse IgG conjugated to tetramethylrhodamine isothiocyanate (TRITC) 1:200 (Sigma), and rabbit anti-goat IgG conjugated to Alexa 488 (Invitrogen).

Immunohistochemistry experiments on normal brain or tumour samples were performed using the antiMARK4L (1:500/1:1.000) and the anti-MARK4S $(1: 500 / 1: 600)$ antibodies.

\subsection{Protein extraction and immunoblotting}

Proteins were extracted from cell lines and tissue samples by lysis buffer. 20 or $25 \mu \mathrm{g}$ of proteins from each sample were resolved under reducing conditions and underwent immunoblotting procedure as described by Magnani et al. [19]. Membranes were washed in PBS-T $\left(100 \mathrm{mM} \mathrm{NaCl}, 80 \mathrm{mM} \mathrm{Na}_{2} \mathrm{HPO}_{4}\right.$, $20 \mathrm{mM} \mathrm{NaH} \mathrm{PO}_{4}, 0.3 \%$ Tween 20) and incubated in $5 \%$ skimmed milk in PBS-T to block non-specific binding. Primary and secondary antibodies were diluted in PBS-T or $1 \%$ skimmed milk in PBS-T. The intensity of the bands was measured using the software ImageJ (freely available at http://rsbweb.nih.gov/ij/). For relative semi-quantitative analysis, MARK4L protein expression was normalized on GAPDH protein expression.

\subsection{Immunofluorescence}

For immunofluorescence (IF) analysis, glioma and normal cell lines were processed as described in Magnani et al. [19].

GBM CSCs and NSCs were fixed as described for the other cell lines but without prior treatment with microtubule-stabilising buffer. For RNA degradation, cells were permeabilised with $0.1 \%$ Triton X-100 for $5 \mathrm{~min}$ and treated with $800 \mu \mathrm{g} / \mathrm{ml}$ RNase A (Sigma) and $5 \mu \mathrm{l}$ RNase Cocktail (Ambion, Austin, USA) in PBS for $30 \mathrm{~min}$ at room temperature (RT).

\subsection{Immunohistochemistry}

Human normal brain specimens were fixed in $4 \%$ paraformaldehyde (PFA) and $0.1 \mathrm{M}$ phosphate buffer $(\mathrm{PB} ; \mathrm{pH} 7.2)$, embedded in paraffin and sectioned $(10 \mu \mathrm{m})$ on a microtome.

After deep anaesthesia, the animals were perfused transcardially with $4 \%$ PFA in $0.1 \mathrm{M}$ PB. Dissected brains were post-fixed in 4\% PFA for 12 hours, embedded in paraffin and sectioned $(10 \mu \mathrm{m})$.

All tissue sections were dewaxed in xylene, rehydrated, and treated in a microwave oven in $0.01 \mathrm{M}$ Na-citrate, pH 6.0. After inhibition of the endogenous peroxidases with $1 \% \mathrm{H}_{2} \mathrm{O}_{2}$, sections were incubated in $1 \%$ BSA (Sigma) with $0.2 \%$ Triton X-100 for 1 hour, and then incubated overnight with primary antibodies at $4^{\circ} \mathrm{C}$ in a humid chamber. The antibody staining was revealed using a biotinylated secondary antibody diluted with $0.1 \%$ BSA in PBS. The avidin-biotinperoxidase protocol (ABC; Vector Labs, Burlingame, CA, USA) was followed, using diaminobenzidine (DAB) (Sigma) as the chromogen. 
Formalin-fixed paraffin-embedded tumour tissues were sectioned at $3 \mathrm{~mm}$ onto positively charged slides (Superfrost plus, Menzel-Glaser, Germany) and subjected to heat-induced epitope retrieval with citrate at a $\mathrm{pH}$ of 6.0. After inhibition of the endogenous peroxidases, slides were blocked for $30 \mathrm{~min}$ (Novolink Polymer Detection Systems, Leica Microsystems and Menarini Diagnostics) and incubated with anti-MARK4L antibody overnight at $4^{\circ} \mathrm{C}$ or with antiMARK4S antibody for 1 hour at RT. For detection, the Novolink Polymer Detection System was used. Immunohistochemical data from tumour tissues were independently evaluated by two investigators.

\subsection{Statistical analysis}

Real-time PCR and immunoblotting experiments were performed in triplicate for each sample; values with standard deviations exceeding $0.5 \%$ or standard errors exceeding $0.3 \%$ were excluded and the experiments repeated. Wilcoxon signed rank, Mann-Whitney and Kruskall Wallis tests were used to compare gene expression data; differences between experimental groups were considered significant when $p<0.05$. All statistical analyses were performed using StatistiXL 1.8 for Microsoft Excel (http://www.statistixl.com).

\section{Results}

\subsection{Mutation analysis of MARK4 genomic sequence}

To determine whether mutations could affect MARK4 activity or favour MARK4L isoform expression in gliomas [14], we sequenced both the MARK4 functionally relevant coding regions and the alternative splice sites. A subset of 12 glioma cell lines and 12 glioma tissues with different malignancy grades [26] were tested.

We primarily screened the MARK4 kinase domain (exons 2-10 and flanking intronic regions) and the ubiquitin-associated (UBA) domain (exons 10-12 and flanking intronic junctions). We also screened exon 13 as suggested by data in the literature [27]. No sequence variations were detected in any of the investigated samples, with the exception of a c. $1101 \mathrm{G}>\mathrm{C}$ synonymous substitution in exon 11 from a glioblastoma cell line (GBM), which does not affect the splicing process. To test whether mutations could affect
MARK4 genomic regions involved in exon 16 alternative splicing, favouring the production of the $\mathrm{L}$ isoform, the mutational screening was extended to exons 15, 16 and 17, IVS16 and IVS17, leading to an overall coverage of the MARK4 coding sequence greater than $70 \%$. We found only a previously unreported single nucleotide alteration within intron 16 (c.1878$61 \mathrm{G}>\mathrm{A}$ ) in 8 glioma samples. This sequence change does not affect the splicing process, as was confirmed by direct sequencing of the MARK4 transcript. Finally, because the MARK4 gene is characterized by short introns that could potentially be retained in the mature mRNA, intron retention between exons 3-4 (152 bp), 5-6 (90 bp) and 11-12 (91 bp) was tested by PCR (and occasionally by direct sequencing) of cDNA, but no splicing errors were detected.

The lack of MARK4 sequence alterations and targeted genomic rearrangements [18] prompted us to evaluate the MARK4L and $\mathrm{S}$ expression profile by real-time PCR, immunoblotting and immunohistochemistry, in order to investigate the post-trascriptional regulation of the MARK4 isoforms in the set of 21 glioma cell lines and 36 glioma biopsies, grouped for WHO diagnosis and grade as reported in Tables 1A and $\mathrm{B}$.

\subsection{Imbalance between MARK4L and MARK4S transcripts in glioma cell lines and tissues}

MARK4 transcripts were quantitatively evaluated in the panels of primary glioma cell lines and glioma tissue samples by real-time PCR.

The results from the glioma cell lines (Figs. 1A and B) indicated that, despite considerable heterogeneity among samples, MARK4L is the prevalent isoform and is over-expressed in 16 out of 21 cell lines $(75 \%)$ when compared with NHNPCs $(p=0.03$, Wilcoxon test). In contrast to our previous mRNA data, which were achieved using a semi-quantitative approach [14], we found that the $\mathrm{S}$ isoform of MARK4 is expressed concurrently with but at lower levels than MARK4L. We determined that MARK4S expression is significantly lower in both non GBM and GBM cell lines when compared with NHNPCs ( $p=0.00001$, Wilcoxon test).

Real-time PCR data from tumour biopsies (Figs. 1C and D), compared with data from HNB, confirmed the heterogeneous expression of both MARK4 isoforms as well as the previously noted MARK4L predominance. We did not find statistically signifi- 

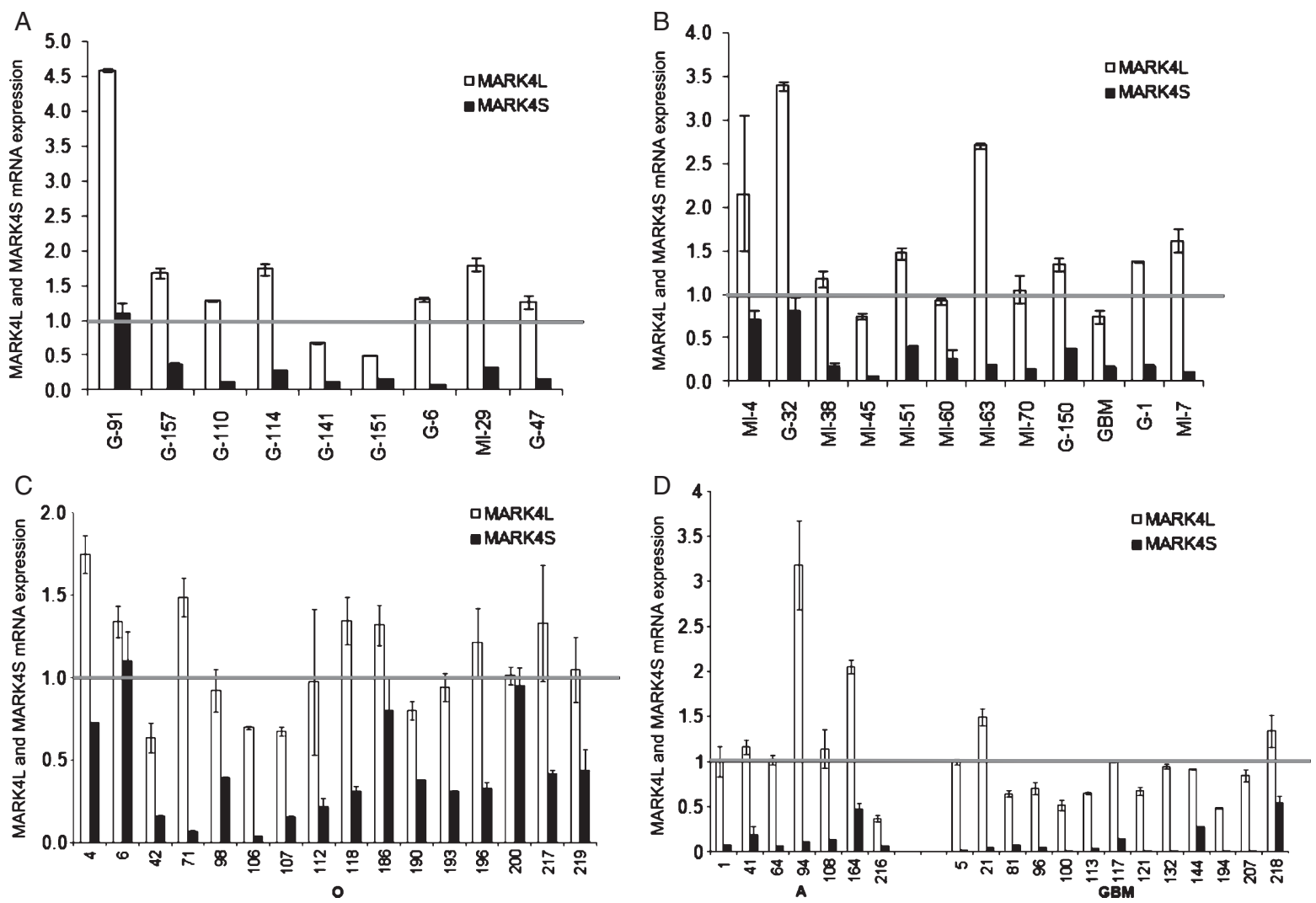

Fig. 1. MARK4L and MARK4S mRNA expression levels. MARK4L (white bar) and MARK4S (black bar) mRNA expression levels in (A) non GBM and (B) GBM cell lines compared with NHNPCs (set as 1 and represented as a horizontal grey line) and in (C) O and (D) A and GBM tissues compared with HNB (set as 1 and represented as a horizontal grey line). Expression data from glioma cell lines were normalized to GAPDH for both MARK4 isoforms, and relative mRNA levels were determined using the $\Delta \Delta \mathrm{Ct}$ method. Expression data from glioma tissues were normalized to GAPDH and $\beta$-actin and analysed by the $\Delta \mathrm{Ct}$ method. Data are expressed as mean \pm standard deviation.

cant differences in MARK4L expression among the three glioma subgroups, although a slight decrease in median expression levels of MARK4L (A: 1.14; O: 1.03; GBM: 0.85) was observed. In contrast, MARK4S expression levels decreased in glioma samples compared with HNB ( $p=0.00001$, Wilcoxon test $)$. Specifically, grade II O had a median value of 0.35 , grade II/III A a median value of 0.11 , and grade IV GBM a median value of 0.03. Interestingly, in the astrocytic tumours (A and GBM) (Fig. 1D) the MARK4S expression was inversely correlated with the tumour grade ( $p=0.04$, Mann-Whitney test).

\subsection{Immunodetection confirms MARK4L prevalence in glioma cell lines and tissues}

The results of semi-quantitative IB on glioma cell lines and tissues are reported in Fig. 2. Consistent with the mRNA data, MARK4L protein was overexpressed in most of the non GBM and GBM cell lines compared with NHNPCs $(p=0.007$, Wilcoxon test) (Fig. 2A). In glioma tissues, MARK4L expression was slightly decreased in GBM samples when compared with A samples, although the differences among the three glioma subgroups were not statistically significant (median values: A: 1.20, O: 0.71, GBM: 0.40) (Fig. 2B). A representative immunoblot of MARK4L expression in tissue samples is shown in Fig. 2C.

The anti-MARK4S antibody non-specifically recognized too many bands in both glioma cell lines and tissue samples (Fig. 2D). We thus performed mass spectrometry analyses to identify the specific band corresponding to the MARK4S protein (Supplementary Information). However, because of weak MARK4S expression and the compactness of the bands, quantification proved very difficult, particularly for tissue 

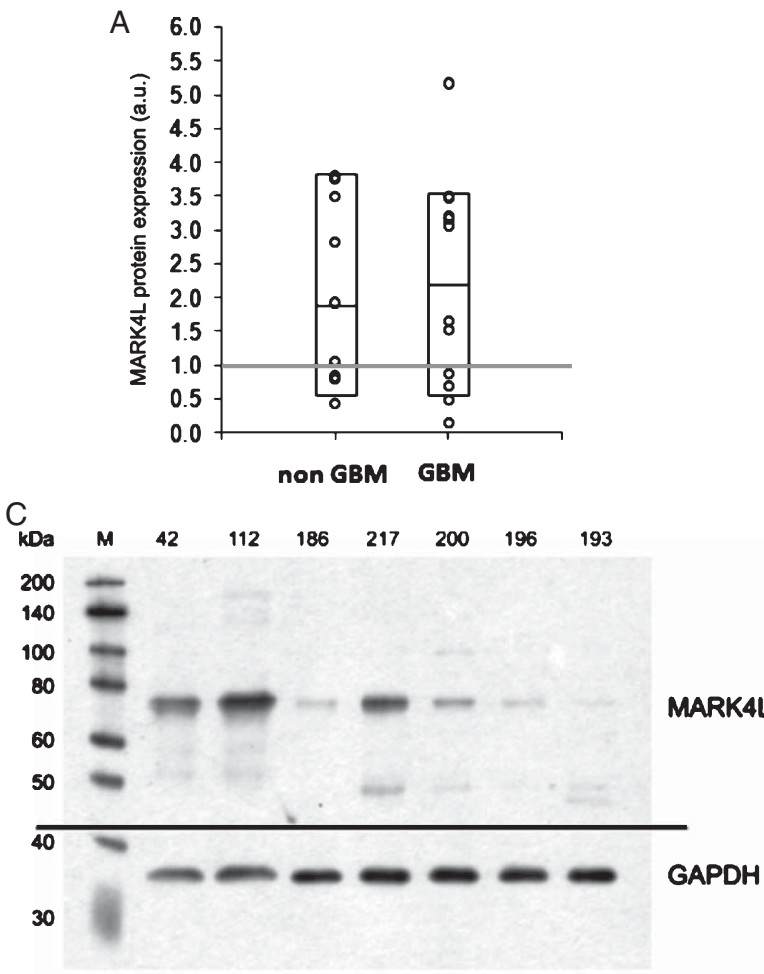

B
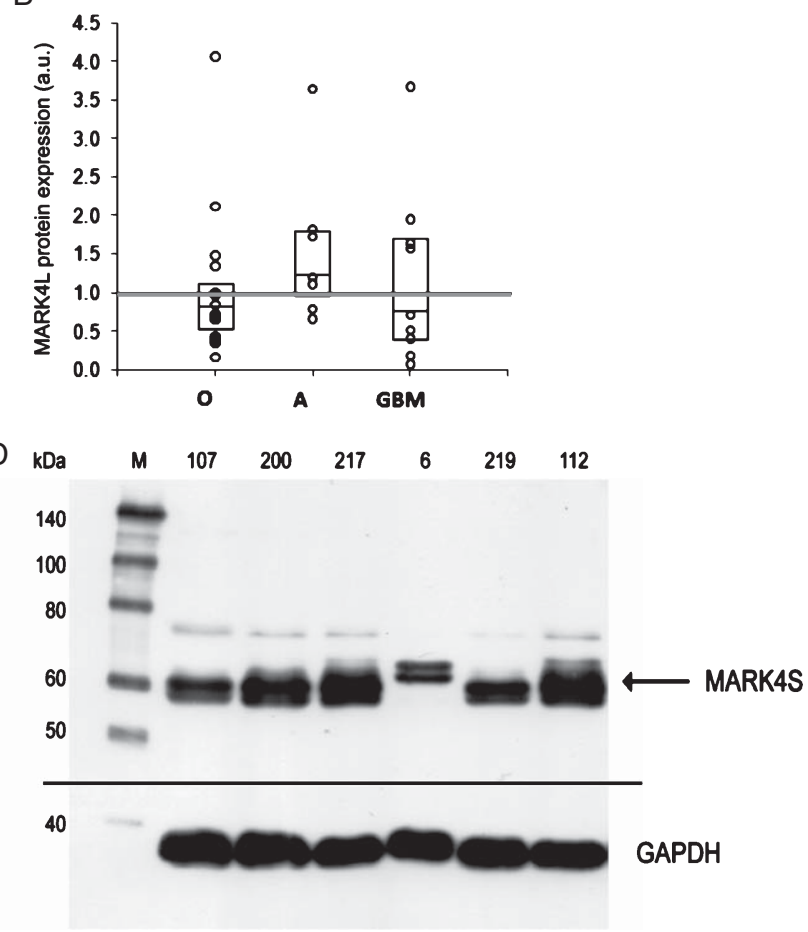

Fig. 2. Relative MARK4L protein expression measured by immunoblotting. (A) non GBM and GBM cell lines compared with NHNPCs (set as 1 and represented as a horizontal grey line). (B) O, A and GBM tissues compared with HNB (set as 1 and represented as a horizontal grey line). (C) Representative MARK4L immunoblot of O tissue samples (42, 112, 186, 217, 200, 196, 193). (D) Representative MARK4S immunoblot of $\mathrm{O}$ tissue samples $(107,200,217,6,219,112)$. The membrane was cut (black lines) after the blocking step and incubated with the appropriate antibodies. M, molecular weight ladders (kDa).

samples. Nevertheless, the IB results were sufficiently reliable to confirm the MARK4S expression profile obtained by real-time PCR (data not shown).

In vivo IHC on matched paraffin-embedded sections was performed to evaluate the expression levels and the intra-tumour cell localisation of MARK4L and MARK4S. The results confirmed that both the $\mathrm{L}$ and $\mathrm{S}$ isoforms of MARK4 are heterogeneously expressed among and within tumours and that MARK4L is the prevalent isoform with the highest composite scores (Table 2). All of the samples, with the exception of GBM 144, were labelled by the anti-MARK4L antibody; MARK4S was instead undetectable in 7 out of 32 analysed cases (22\%). Specifically, 2 out of $15 \mathrm{O}$ samples (71 and 106) (Table 2 and Fig. 1C) and 5 out of 13 GBM samples (5, 100, 132, 194 and 207) (Table 2 and Fig. 1D) were negative for MARK4S. Moreover, IHC showed that MARK4L had both a perinuclear and nuclear localisation in nearly all of the processed tumours, in addition to a nucleolar locali- sation in several tumour cells (Fig. 3A). In contrast, MARK4S was mainly localised to the perinuclear region of tumour cells (Fig. 3B). Both MARK4S and MARK4L antibodies also labelled some differentiated neurons, in particular pyramidal neurons, entrapped in the tumour mass (Figs. 3A and B), whereas only MARK4L detected endothelial cells (Fig. 3A).

\subsection{A high MARK4L/MARK4S ratio tags the undifferentiated phenotype of GBM, GBM CSCs and NSCs}

We further analyzed the MARK4L and S expression levels in a set of GBM CSCs, which are known to reproduce the genotypic and phenotypic features of glial tumours [22, 29], compared with astrocytic tumours (A and GBM). Real-time PCR data (Fig. 4A) showed that MARK4L is the predominant isoform. Interestingly, MARK4S expression is inversely correlated with both glioma malignancy and with the undifferentiated 
Table 2

MARK4 L and MARK4 S immunohistochemical data

\begin{tabular}{|c|c|c|c|c|c|c|c|}
\hline \multirow[b]{2}{*}{ Sample } & \multirow[b]{2}{*}{$\begin{array}{l}\text { WHO Diagnosis/ } \\
\text { Grade }\end{array}$} & \multicolumn{3}{|c|}{ MARK4L } & \multicolumn{3}{|c|}{ MARK4S } \\
\hline & & $\begin{array}{l}\text { Staining } \\
\text { intensity }\end{array}$ & $\begin{array}{c}\text { Labelling } \\
\text { extent }\end{array}$ & $\begin{array}{c}\text { Composite } \\
\text { score }\end{array}$ & $\begin{array}{l}\text { Staining } \\
\text { intensity }\end{array}$ & $\begin{array}{c}\text { Labelling } \\
\text { extent }\end{array}$ & $\begin{array}{l}\text { Composite } \\
\text { score }\end{array}$ \\
\hline 4 & $\mathrm{O} / \mathrm{II}$ & 2 & 2 & 4 & 1 & 2 & 2 \\
\hline 6 & $\mathrm{O} / \mathrm{II}$ & 3 & 3 & 9 & n.e. & n.e. & n.e. \\
\hline 42 & $\mathrm{O} / \mathrm{II}$ & 3 & 3 & 9 & 1 & 1 & 1 \\
\hline 71 & $\mathrm{O} / \mathrm{II}$ & 3 & 2 & 6 & neg & neg & \\
\hline 98 & $\mathrm{O} / \mathrm{II}$ & 2 & 3 & 6 & 1 & 2 & 2 \\
\hline 106 & $\mathrm{O} / \mathrm{II}$ & 3 & 2 & 6 & neg & neg & \\
\hline 107 & $\mathrm{O} / \mathrm{II}$ & 2 & 2 & 4 & 3 & 2 & 6 \\
\hline 112 & $\mathrm{O} / \mathrm{II}$ & 2 & 2 & 4 & 2 & 2 & 4 \\
\hline 118 & $\mathrm{O} / \mathrm{II}$ & 2 & 1 & 2 & 1 & 1 & 1 \\
\hline 186 & $\mathrm{O} / \mathrm{II}$ & 3 & 1 & 3 & 1 & 1 & 1 \\
\hline 190 & $\mathrm{O} / \mathrm{II}$ & 2 & 2 & 4 & 1 & 2 & 2 \\
\hline 193 & $\mathrm{O} / \mathrm{II}$ & 3 & 1 & 3 & 2 & 2 & 4 \\
\hline 196 & $\mathrm{O} / \mathrm{II}$ & 3 & 2 & 6 & 3 & 2 & 6 \\
\hline 200 & $\mathrm{O} / \mathrm{II}$ & 2 & 1 & 2 & 1 & 1 & 1 \\
\hline 217 & $\mathrm{O} / \mathrm{II}$ & 1 & 2 & 2 & 1 & 2 & 1 \\
\hline 219 & $\mathrm{O} / \mathrm{II}$ & 2 & 2 & 4 & 2 & 2 & 4 \\
\hline 1 & PA/II & 3 & 3 & 9 & 2 & 3 & 6 \\
\hline 41 & $\mathrm{~A} / \mathrm{II}$ & n.e. & n.e. & n.e. & n.e. & n.e. & n.e. \\
\hline 64 & $\mathrm{PA} / \mathrm{II}$ & 3 & 2 & 6 & n.e. & n.e. & n.e. \\
\hline 94 & $\mathrm{~A} / \mathrm{II}$ & n.e. & n.e. & n.e. & n.e. & n.e. & n.e. \\
\hline 108 & AA/III & 3 & 1 & 3 & 1 & 1 & 1 \\
\hline 164 & FA/II & 2 & 1 & 2 & 1 & 1 & 1 \\
\hline 216 & $\mathrm{PA} / \mathrm{II}$ & 3 & 2 & 6 & 2 & 2 & 4 \\
\hline 5 & GBM/IV & 2 & 3 & 6 & neg & neg & \\
\hline 21 & giant cell GBM/IV & 2 & 3 & 6 & 2 & 2 & 4 \\
\hline 81 & GBM/IV & 2 & 2 & 4 & 1 & 2 & 2 \\
\hline 96 & GBM/IV & 1 & 1 & 1 & 1 & 1 & 1 \\
\hline 100 & GBM/IV & 3 & 3 & 9 & neg & neg & \\
\hline 113 & GBM/IV & 2 & 2 & 4 & 1 & 1 & 1 \\
\hline 117 & GBM/IV & 2 & 1 & 2 & neg & neg & \\
\hline 121 & GBM/IV & 2 & 2 & 4 & 1 & 1 & 1 \\
\hline 132 & GBM/IV & 3 & 1 & 3 & neg & neg & \\
\hline 144 & GBM/IV & neg & neg & & 2 & 2 & 4 \\
\hline 194 & GBM/IV & 1 & 1 & 1 & neg & neg & \\
\hline 207 & small cell GBM/IV & 1 & 2 & 2 & 1 & 1 & 1 \\
\hline 218 & GBM/IV & 1 & 2 & 2 & 2 & 2 & 4 \\
\hline
\end{tabular}

The staining intensity of a minimum 100 cells from each specimen was visually graded on a scale ranging from 0 to $3(0=$ no staining; $1=$ weak, $2=$ moderate, and $3=$ strong staining). The extent of labelling was scored on the basis of the percentage of immunopositive cells: $0 \leq 5 \%$; $1=6-35 \% ; 2=36-66 \%$ and $3 \geq 67 \%$. A composite score was then obtained by multiplication of the intensity and extent scores as described in Chauhan et al. [28]. Abbreviations: O, oligodendroglioma; PA, pilocytic astrocytoma; A, astrocytoma; AA, anaplastic astrocytoma; FA, fibrillary astrocytoma; GBM, glioblastoma; neg, negative; n.e. not evaluated.

phenotype of tumour cells ( $p=0.001$, Kruskal-Wallis test). As a result of this significant decrease in MARK4S expression, the MARK4L/MARK4S ratio increases progressively (Fig. 4B).

GBM CSCs compared with mouse postnatal NSCs, the most likely glioma cells-of-origin, showed slightly higher levels of MARK4L, while MARK4S was hardly detectable in both stem cell groups (Fig. 4C).
We also evaluated the MARK4L expression profile in terminally differentiated NSCs and GBM CSCs by IB. We found that both differentiated and undifferentiated GBM CSCs shared similar MARK4L protein levels, whereas in NSCs the L isoform became undetectable by the 7th day of differentiation (Fig. 4D). The MARK4S expression profile in GBM CSCs and NSCs was not determined by IB because of the difficulty in 

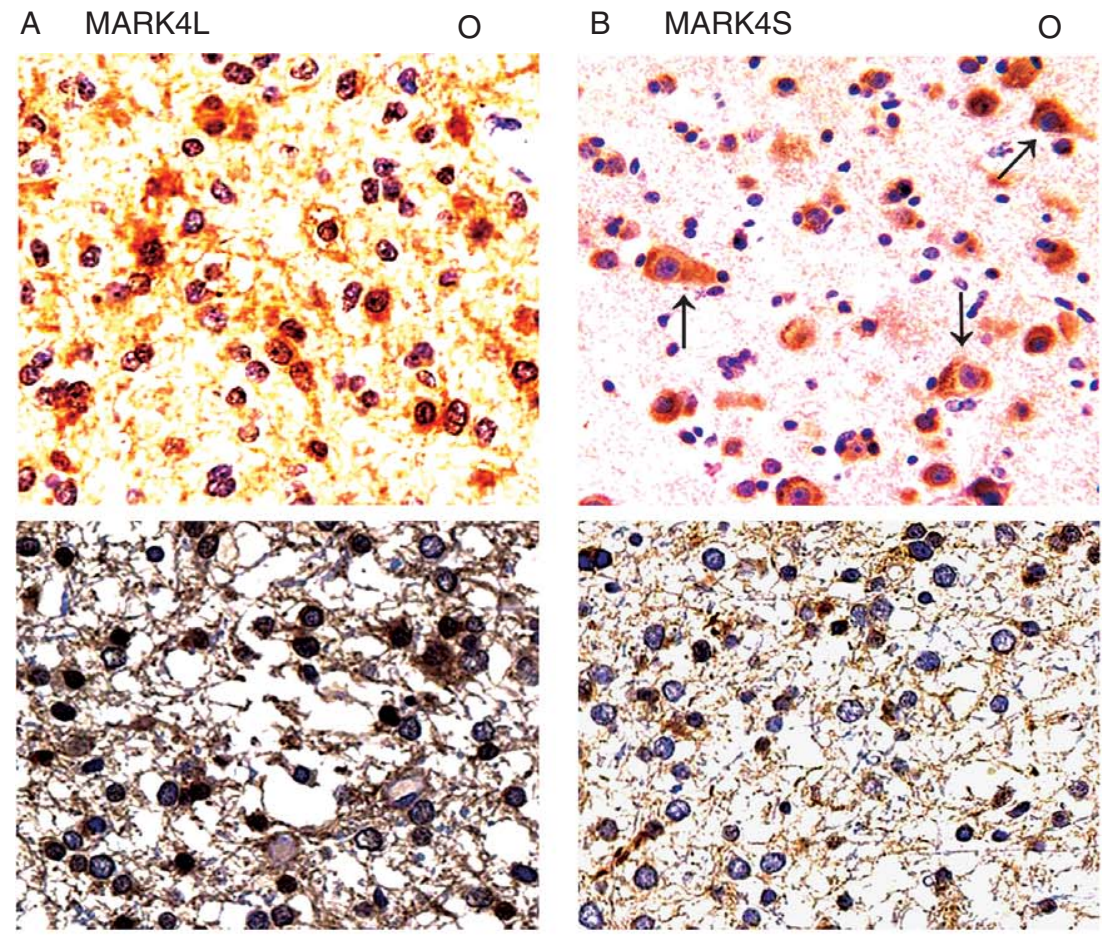

GBM

GBM
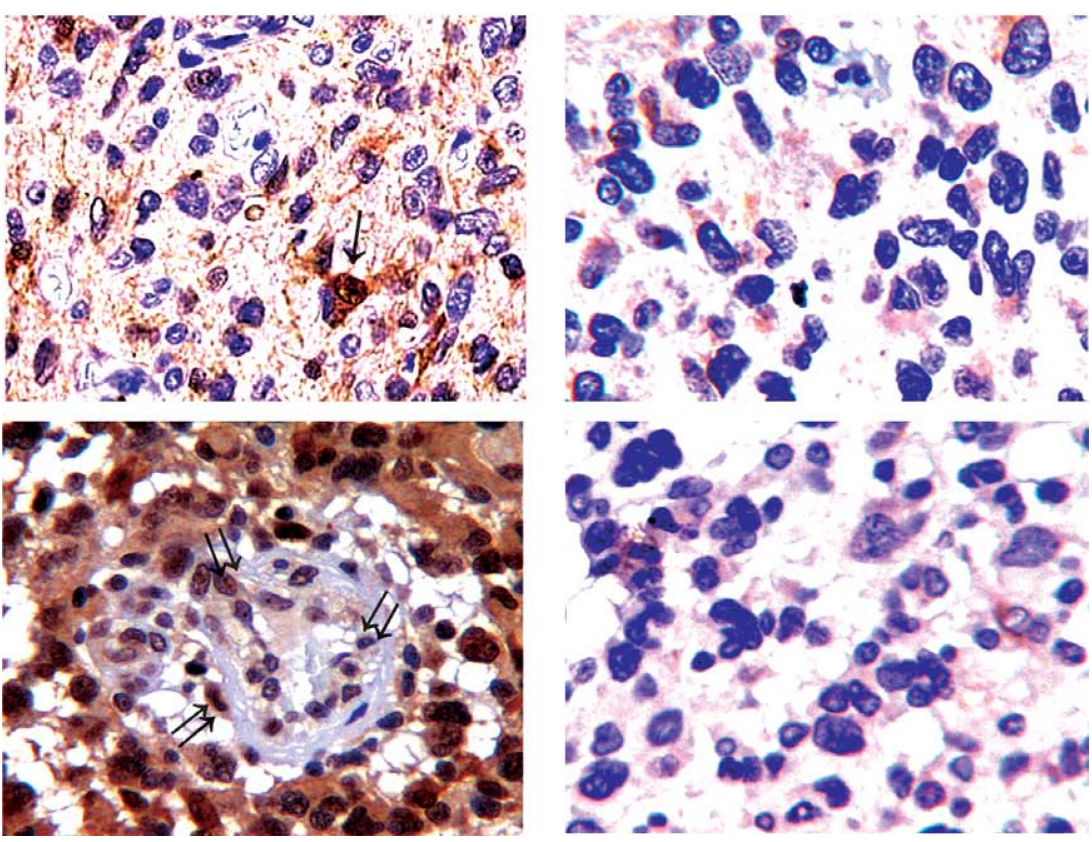

Fig. 3. Representative images of MARK4 immunohistochemistry experiments in glioma tissues. (A) MARK4L and (B) MARK4S labelling of O (samples 193 and 196) and GBM (samples 207 and 113). Arrows indicate neurons entrapped in the tumor mass labelled by both MARK4 antibodies. Double arrows point to endothelial cells expressing MARK4L. IHC was performed using the DAB method with haematoxylin counterstaining. 

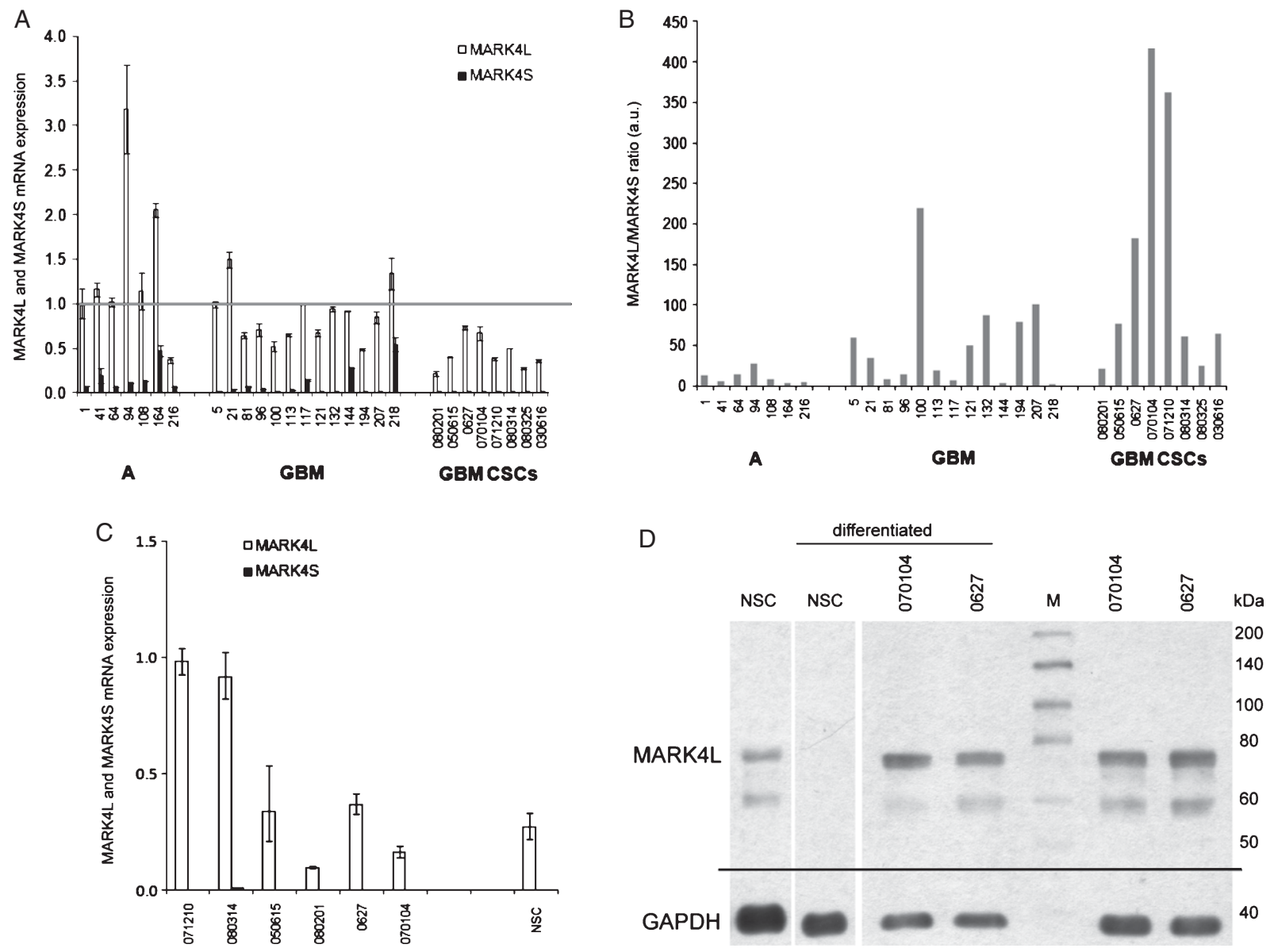

Fig. 4. MARK4 expression profile in GBM CSCs and NSCs. (A) Relative expression of MARK4L (white bar) and MARK4S (black bar) mRNA in A, GBM and GBM CSCs compared with HNB (set as 1 and represented as a horizontal grey line). Data were normalized to GAPDH and $\beta$-actin and analyzed by the $\triangle \mathrm{Ct}$ method. (B) MARK4L/MARK4S mRNA ratio in A, GBM and GBM CSCs. (C) MARK4L (white bar) and MARK4S (black bar) transcript levels in GBM CSCs and mouse NSCs compared with HNB (set as 1). Data were analyzed with the $\Delta \Delta \mathrm{Ct}$ method using $18 \mathrm{~S}$ rRNA as the endogenous control. Real-time data are expressed as mean \pm standard deviation. (D) Immunoblotting for MARK4L in undifferentiated and differentiated GBM CSCs $(070104,0627)$ and NSCs. The membrane was cut (black line) after the blocking step and incubated with the appropriate antibodies. M, molecular weight ladders (kDa).

identifying the specific band due to the low level of MARK4S expression.

\subsection{The alternative MARK4L isoform is expressed in normal brain ventricular and sub-ventricular zones}

We investigated MARK4L and MARK4S expression in both human and rodent tissues from adult and embryonic brain by IHC. The overall distribution of the two MARK4 isoforms was similar in the cortical grey and white matter, but it differed in the embryonic ventricular zone and adult sub-ventricular zone
(SVZ), both of which are known germinal sites in the brain (Fig. 5). In embryos, MARK4L was expressed in some cells located in the ventricular zone (Fig. 5A) and in some post-mitotic neurons in the intermediate zone and in the cortical plate (data not shown). In line with the low levels of MARK4S transcript in cultured NSCs, the S isoform was undetectable in the ventricular zone, although it was expressed in the embryonic post-mitotic neurons (Figs. 5B). Interestingly, MARK4L, unlike MARK4S, was expressed in some cells of the SVZ in adult rodents (Figs. 5C and D).

In the white matter, some glial cells appeared to be immunolabelled for MARK4L (Fig. 5E), while fewer 


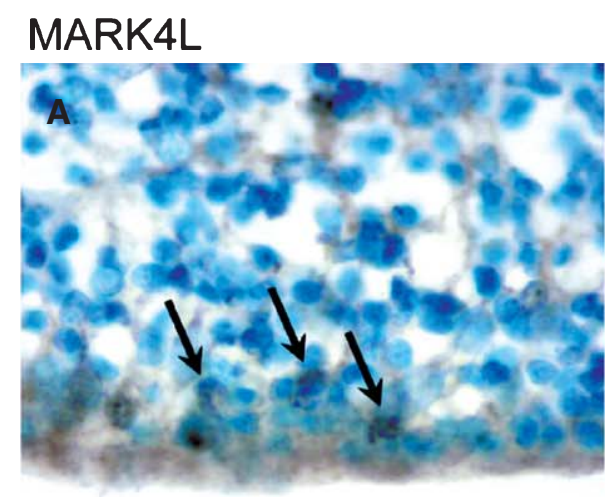

\section{MARK4S}
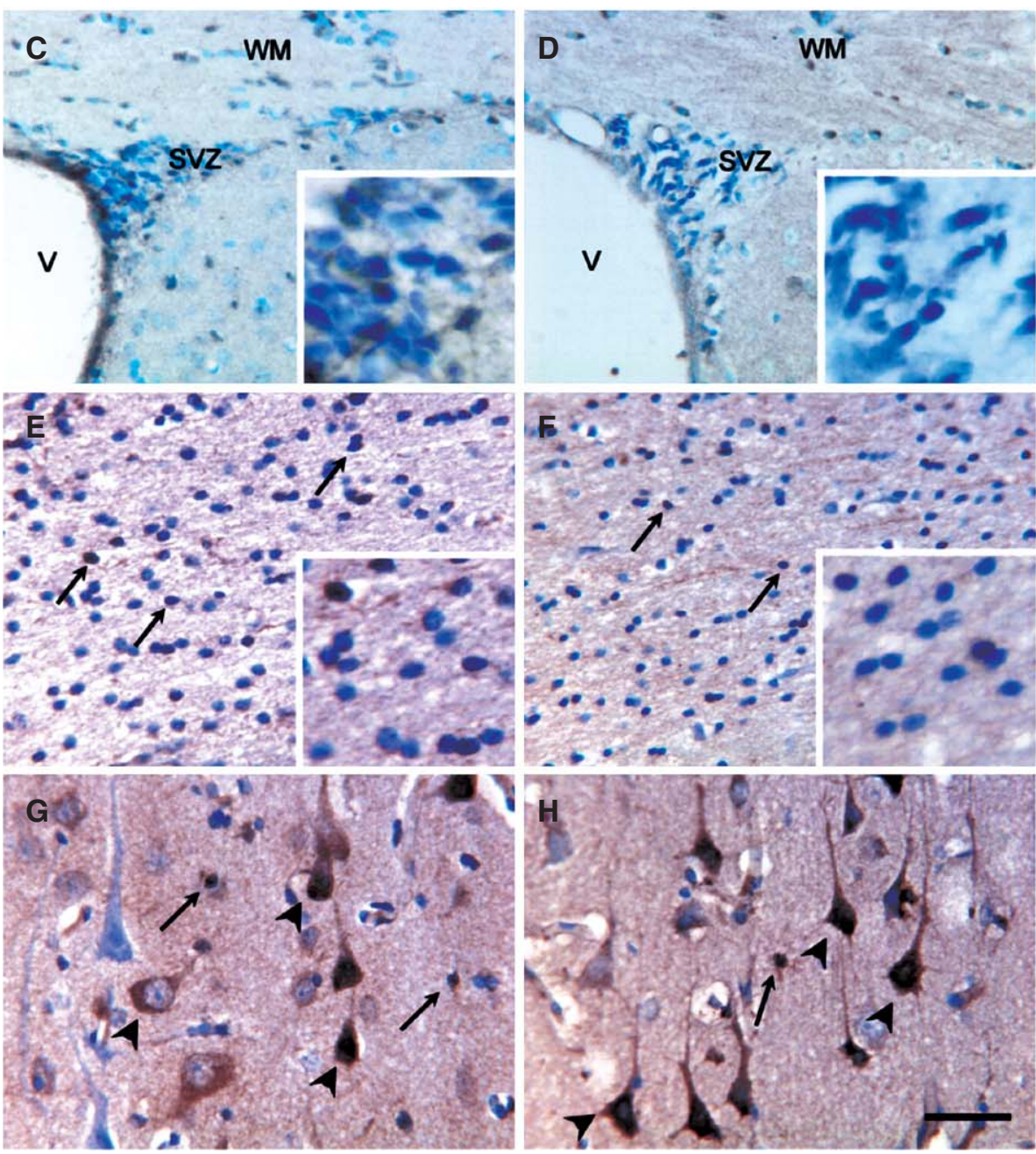

Fig. 5. In vivo expression of MARK4L and MARK4S in human and mouse brain. (A) MARK4L expression in some cells of the ventricular zone in the human embryo (arrows) and (B) lack of MARK4S expression in the same area. (C and high-magnification inset) MARK4L expression in some cells of the SVZ in the adult mouse brain and (D and high-magnification inset) lack of MARK4S expression in the same area. (E and G) MARK4L and (F and H) MARK4S are expressed in some glial cells (arrows) in the white matter of the adult human cerebral cortex. Both proteins are also expressed in several neurons (arrowheads in $\mathrm{G}$ and $\mathrm{H}$ ) and in some glial cells (arrows in $\mathrm{G}$ and $\mathrm{H}$ ) in the gray matter. $\mathrm{V}$, ventricle; SVZ, sub-ventricular zone; WM, white matter. Scale bar $=14.5 \mu \mathrm{m}$ in A, B and in insets in C, D; $74 \mu \mathrm{m}$ in C-H; $44.4 \mu \mathrm{m}$ in insets in E, F. 
cells were MARK4S-positive (Fig. 5F). In the cerebral cortex, both MARK4L and MARK4S antibodies detected a few glial cells and most of the neurons distributed throughout the cortical layers (Figs. 5G and $\mathrm{H}$ ).

\subsection{The MARK4L isoform is delineated as a tumour marker through nucleolar association}

New evidence illuminating the role of MARK4 isoforms has been provided by IF studies. We demonstrate herein that MARK4S localises to the centrosome and midbody in glioma cell lines (Fig. 6A), as has been previously shown for MARK4L [19]. However, in contrast to the $\mathrm{L}$ isoform, no immunoreactivity with nucleolar structures was observed for MARK4S in glioma cell lines (Fig. 6B). IF experiments on normal cells, including human neural progenitors (ReNcellCX), adult fibroblasts and myoblasts, showed that both MARK4 isoforms are undetectable in the nucleoli (Figs. 6C-E), but are associated to the centrosome and midbody as in glioma cell lines (Figs. 6F-H). Furthermore, we investigated the MARK4L nucleolar localisation in GBM CSCs, NSCs and their differentiated counterparts. We performed double-IF with anti-MARK4L and antinucleolin antibodies and found a specific nucleolar association of MARK4L in 2 out of 3 GBM CSC samples. We also found that the MARK4L nucleolar signal is stronger in differentiated cells than in their undifferentiated progeny (Figs. 6I and J). In contrast, MARK4L was never detectable in the nucleoli of NSCs (Figs. 6K and $\mathrm{L}$ ). Hence, the nucleolar association appears to be a specific feature of the $\mathrm{L}$ isoform of MARK4 and is detectable only in glioma cells.

We also determined by IF that RNase treatment of fixed MI-4 GBM cells abolishes the nucleolar localisation of both MARK4L and nucleophosmin (NPM), suggesting that MARK4L may be physically associated with nucleolar RNAs or ribonucleoproteins (Figs. 6M and N). In contrast, the midbody localisation of MARK4L was maintained in RNase treated cells (Fig. 6M).

\section{Discussion}

We previously reported that the up-regulation of MARK4L noticed in glioma cannot be explained by copy-number variations [18]. Our sequence analysis of $M A R K 4$, intended to disclose whether the enhanced kinase expression is set in motion by mutations, failed to reveal any alteration. Accordingly, in 91 GBM samples analysed for 518 protein kinase genes by the Cancer Genome Atlas [27], only a splice-site mutation in exon 13 affected MARK4. Other mutations hitting exons 5, 8, 9 and 12 have been found in different tumours [30], although their role in the tumour process has not been dissected. We therefore postulated that other mechanisms, acting at the posttranscriptional level, may favour MARK4L expression to the detriment of MARK4S, likely conferring a selective advantage during tumour development and progression. In line with previous data, this study reaffirms that the L splice variant is the over-expressed isoform of MARK4 in glioma cell lines and is the more abundant isoform in a wide panel of tumours of different malignancy grades (Tables 1A and B). The slight discrepancy in transcript and protein levels observed between tissues and cell lines is consistent with the known tumour heterogeneity and the remarkable phenotypic diversity of glial tumours [31]. The highly variable expression of MARK4 in different samples may indeed reflect differences in their glioma-initiating cells [32]. Real-time PCR analyses highlighted that both $\mathrm{L}$ and $\mathrm{S}$ isoforms of MARK4 are concurrently expressed in glioma cell lines and tissues. However, unlike the L isoform, MARK4S transcript levels show a significant decrease that is correlated with tumour malignancy. This decrease is evidence of a switch towards MARK4L expression and an associated loss of differentiation (Figs. 1C-D and 4A). A likely hypothesis is that the balance between the MARK4 isoforms is carefully guarded during the normal differentiation program in neural tissue but may be subverted in gliomagenesis. In this context, MARK4 alternative splicing appears to be the most likely mechanism regulating MARK4L and S balance and may be a molecular target of tumour transformation in gliomas [33]. Of the many consequences of alternative splicing in the central nervous system (CNS), a few are reported to underlie both simple and complex diseases, including cancer [34]. A relevant example is provided by taupathies, where the altered ratio of the alternative splicing-derived Tau isoforms, 3R-tau and 4R-tau, is sufficient to cause neurodegeneration and dementia [35]. Interestingly, Tau is a downstream element in the MARK4 protein pathway [4]. In cancer, aberrant splicing events have been implicated in the failure of a class of molecules whose normal function is to control 

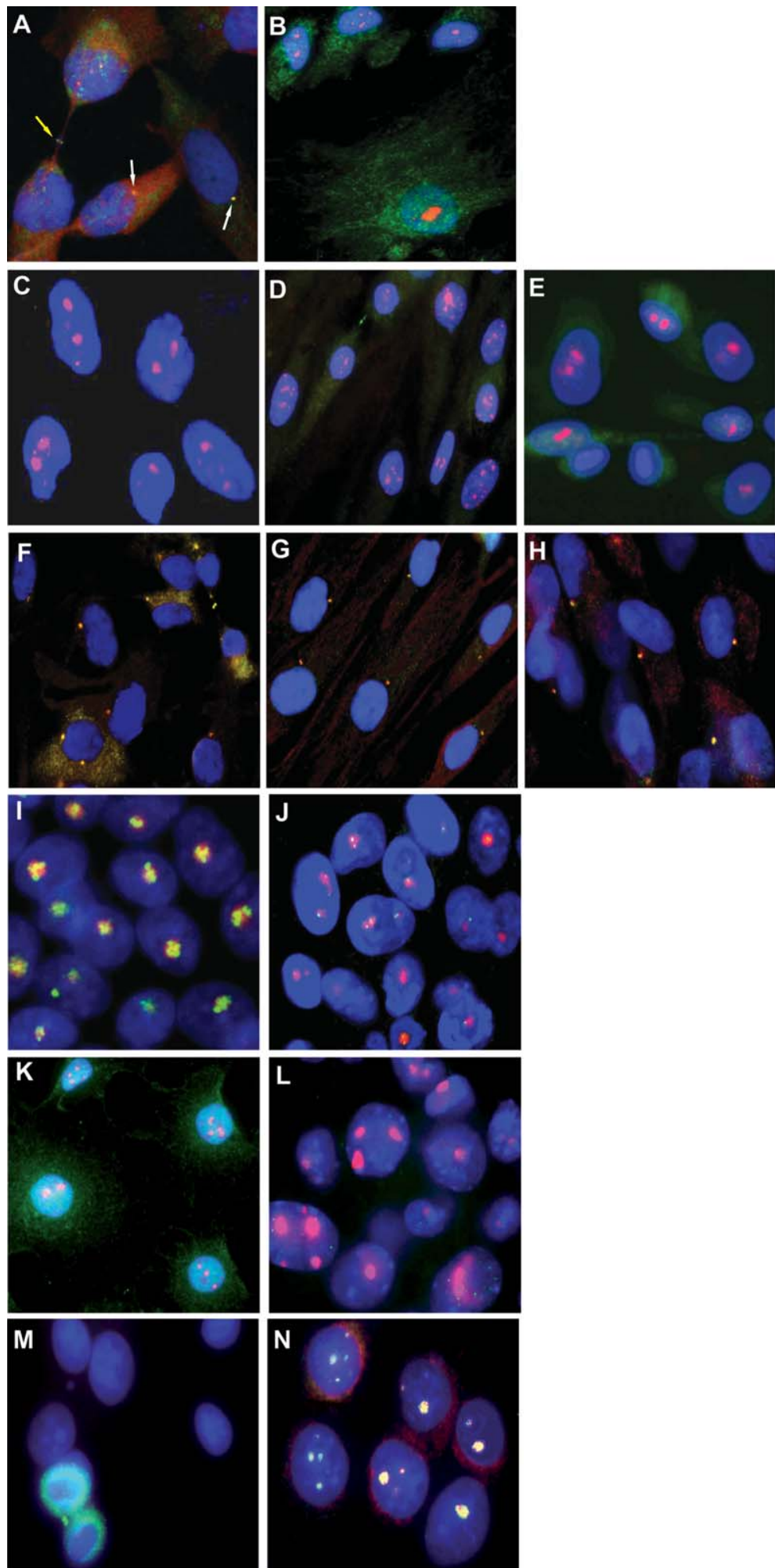

N

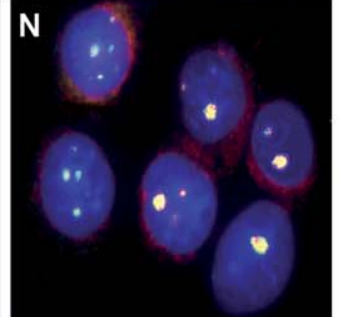

Fig. 6. Representative immunofluorescence images of MARK4L and MARK4S. 
the balance between cell proliferation and differentiation in stem cells and during embryonic development $[32,36]$. Examples include the nerve growth factor TrkAIII variant, which is found in both neural stem cells and neuroblastoma [37], and the caspase $8 \mathrm{~L}$, which is expressed in both hematopoietic stem cells and leukaemias [38]. Brain tumours have also been reported to retain a foetal variant of the neurofibromatosis gene NF1 [39], and foetal forms of the insulin receptor and fibronectin are also maintained in various cancers [40]. Accordingly, we found that MARK4L expression levels are consistently predominant in both GBM CSCs and NSCs, whereas MARK4S expression faded in both cases (Fig. 4C). Notably, under differentiation conditions, while MARK4L expression is switched off in post-mitotic NSC progeny, it is maintained in GBM CSCs (Fig. 4D). This behaviour is reminiscent of that of other brain stem cell markers such as CD133 and nestin during differentiation assays $[41,42]$. This evidence, in addition to the in vivo localisation of the sole MARK4L isoform in a subset of adult and embryonic ventricular/sub-ventricular zone cells (Figs. 5A-D), not stained by MARK4S, suggests that this MARK4 expression profile is part of a stemness-expression program which may be maintained by glioma cells. Therefore, we may hypothesize that a few of the GBMs in our panel may have originated from transformed neural stem cells, as they express almost exclusively MARK4L and show a close spatial relationship with the SVZ by magnetic resonance imaging on the carrier patients (Table 1B). In addition, the in vivo detection of both MARK4L and $\mathrm{S}$ in few glial cells and human neurons (Figs. 5E-H and arrows in Fig. 3) associates MARK4S expression with neural differentiation, extending our published data on mouse CNS [12].

It has recently been pointed out that alternative splicing products that are involved in the maintenance of chromosome segregation fidelity can contribute to chromosomal instability (CIN) [43]. These transcriptional variants are often over-expressed, causing multipolar mitoses and mis-segregation in cancer cell lines and tissues. The MAD1ß and Aurora B isoforms provide excellent examples [44, 45]; these isoforms lead first to errors in the mitotic spindle checkpoint and ultimately to CIN. Centrosome abnormalities are also caused by an imbalance in splice variants of proteins that are key centrosome regulators, like TrkAIII, which is over-expressed in advanced neuroblastoma and primary glioblastoma [46], and NEK2A [47], which has been proposed as a tumour marker and is abnormally expressed in most cancer cell lines and tumours. In keeping with this evidence, we have previously shown a connection between the alternatively spliced MARK4L isoform and aberrant centrosomes in glioma cell lines by co-immunofluorescence experiments with anti-MARK4L and $\gamma$-tubulin antibodies, suggesting that there is a link between the alternatively spliced kinase and the mitotic instability frequently observed in human glioma [19]. In a continued effort to dissect the similar, complementary or antagonistic properties of MARK4L and S in glioma, the present study demonstrates that both MARK4 isoforms are localised to the centrosome and midbody in both glioma cell lines and various normal cells, including neural progenitors (Figs. 6A and $\mathrm{F}-\mathrm{H}$ ). Thus, the presence of MARK4 protein in these compartments is neither isoform- nor tumour-specific and suggests that the main function of the kinase impacts centrosome and midbody activity. Like the other members of the MARK family, MARK4 is a key regulator of the dynamics of microtubules, including the mitotic spindle microtubules nucleated by centrosomes. MARK4 also participates in the depolymerisation of microtubules during anaphase by phosphorylating MAPs, many of which have been identified in the mitotic spin-

(Fig. 6 continued). (A) Double MARK4S (green) and $\gamma$-tubulin (red) immunostaining of the MI-60 cell line showing the colocalisation of the kinase with the midbody (yellow arrow) and centrosomes (white arrow) near the nucleus. (B) In G-91 cells, MARK4S does not exhibit colocalisation with the nucleoli, identified by the nucleolin red signals. (C-E) Co-labelling of both MARK4 isoforms (green) and nucleolin (red) in normal cells. (C) MARK4S does not colocalise with the nucleoli in ReNcellCX. MARK4L does not localise to the nucleoli of (D) adult fibroblasts or (E) myoblasts. (F) MARK4S and $(\mathrm{G}-\mathrm{H})$ MARK4L (green) colocalise with $\gamma$-tubulin (red) in the midbody and centrosomes of matched normal cells. (I-L) Representative images of MARK4L immunofluorescence in human GBM CSCs and mouse NSCs. Doubleimmunostaining of MARK4L (green) and nucleolin (red) in GBM CSCs shows (I) strong MARK4L signals in the differentiated progeny and (J) a faint labelling of the kinase in the nucleoli of undifferentiated GBM CSCs. (K and L) MARK4L is not detectable in the nucleoli of either differentiated or undifferentiated mouse NSCs. (M and N) Effect of RNase treatment on MARK4L and nucleophosmin (NPM) sub-cellular localisation in the MI-4 GBM cell line. (M) Absence of both MARK4L (green) and NPM (red) fluorescent signals in the nucleoli of RNase treated cells, while MARK4L midbody association is maintained. (N) Both MARK4L and NPM localise to the nucleoli of RNase-untreated cells. Nuclei are counterstained with DAPI. Magnification $=63 \times$. 
dle [48]. In addition to this main function, most likely shared by the two MARK4 isoforms, the association of only the MARK4L isoform to nucleoli in glioma and in both differentiated and undifferentiated GBM CSCs (Figs. 6B-L) suggests that in tumours the $\mathrm{L}$ variant has isoform-specific functions and interactions with nucleolar components. This hypothesis is preliminarily supported by experiments showing MARK4L depletion in the nucleoli following treatment with RNase (Figs. 6M and N). In keeping with the general view that the nucleolar localisation would result from retention rather than targeting to this compartment [49], the analysis of whole-proteome predicted nuclear/nucleolar localisation signals (NLS/NoLS) has not revealed any of these consensus sequences in MARK4 kinase. It is worth noting that MARK4 activity is regulated by post-translational modifications, such as phosphorylation and ubiquitinylation, that take place also in the nucleolus, suggesting that MARK4L specific nucleolar localisation in tumours may account not only for the MARK4L and S expression profiles but also for possible differences in their activation patterns.

\section{Conclusions}

In conclusion, these data provide evidence on disruption of the MARK4L/MARK4S balance in gliomas, which is particularly striking in GBM and GBM CSCs. Moreover, the in vivo localisation of the sole MARK4L isoform in the brain ventricular zone enriched in stem cells suggests that this MARK4 expression profile is part of a stemness-expression program which may be maintained by glioma cells. The altered ratio of MARK4 isoforms in glioma may favour the presence of MARK4L to the nucleoli, an exclusive feature of cancer cells. Ongoing experiments investigating the significance of MARK4 sub-cellular localisation in glioma by isoform-specific over-expression and siRNA-mediated depletion will allow us to understand the intricate coupling of the two isoforms. Further studies are needed to comprehend MARK4 activation state and to define the mechanisms underlying the altered MARK4 alternative splicing in glioma.

\section{Acknowledgments}

We would like to thank Dr. Delfina Tosi of the Pathology Unit, Department of Medicine, Surgery and Dentistry, Università degli Studi di Milano, for excel- lent technical assistance with the IHC experiments; Prof. Andrea Gallina of the Department of Medicine, Surgery and Dentistry, Università degli Studi di Milano and Dr. Marco Patrone for help in the preparation of the MARK4L construct; Dr. Elisa Maffioli, of the Department of Animal Pathology, Hygiene and Veterinary Public Health, Università degli Studi di Milano, for checking the antibody validation data. We thank the Galliera Genetic Bank and Fondazione IRRCCS Istituto Neurologico "C. Besta"- "Telethon Genetic Biobank Network" supported by Italian Telethon grants (project no. GTB07001) for providing us with normal human fibroblasts and myoblasts. This study was supported by a grant from the Associazione Italiana per la Ricerca sul Cancro (Grant No. 4217 to L.L. for 2008). L.F, D.R, L.M are PhD students of Experimental Pathology and Neuropathology at the Università degli Studi di Milano.

\section{Supplementary information}

\section{GenScript customised anti-MARK4L antibody validation}

Full-length MARK4L cDNA was amplified by PCR from the total cDNA of the ReNcellCX cell line using $P f u$ DNA polymerase (Promega) and MARK4Lspecific primers also harbouring BamHI and EcoRI restriction sites. MARK4L cDNA was then digested, purified and cloned into the BamHI/EcoRI site of the mammalian expression vector pcDNA4/HisMax (Invitrogen). This vector includes a cleavable Nterminal Xpress ${ }^{\mathrm{TM}}$ tag for the detection of the recombinant protein with mouse anti-Xpress ${ }^{\mathrm{TM}}$ antibody $(1: 5.000)$. Direct sequencing confirmed that MARK4L cDNA was properly orientated, in frame with the fusion tag and without sequence variations. HEK293T cells were cultured in DMEM supplemented with $10 \% \mathrm{FBS}$ and $1 \%$ penicillin-streptomycin at $37^{\circ} \mathrm{C}$ in a $5 \% \mathrm{CO}_{2}$ atmosphere. Cells were seeded on a $6-\mathrm{cm}$ plate and transfected at approximately $30 \%$ confluence by calcium-phosphate precipitation, using $6.5 \mu \mathrm{g}$ of plasmid DNA mixed with $22 \mu \mathrm{l}$ of $2 \mathrm{M} \mathrm{CaCl}_{2}$ and $180 \mu \mathrm{l}$ of $2 \mathrm{X}$ HEPES-buffered saline (HBS) in a final volume of $500 \mu \mathrm{l}$. This solution was incubated for $30 \mathrm{~min}$ at RT and then added to the cells in culture. The medium was removed 24 hours after transfection and cells were incubated with fresh complete medium 


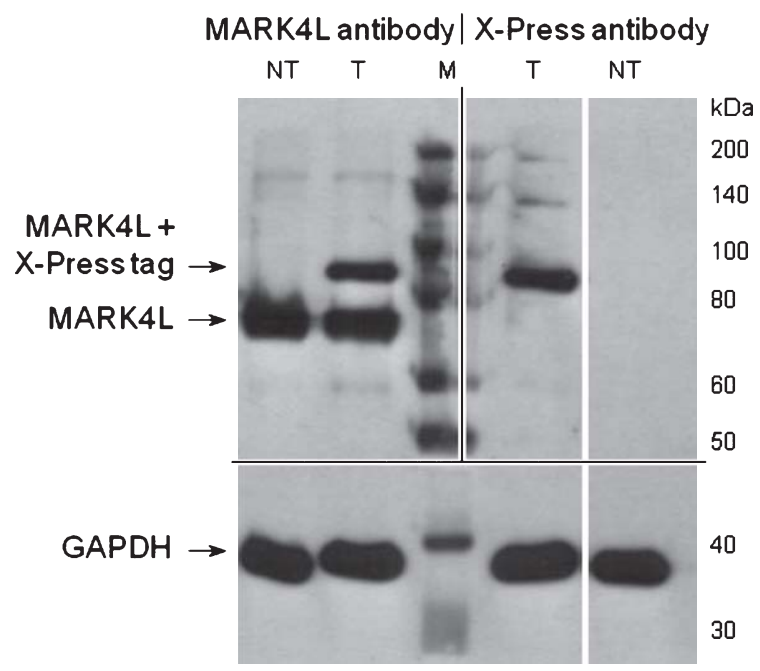

Supplementary Figure 1. Anti-MARK4L antibody validation. Both the anti-MARK4L and anti-Xpress antibodies recognise the overexpressed MARK4L protein in immunoblotting experiments. HEK293T cells were transfected with plasmid DNA encoding the fusion protein MARK4L + Xpress tag. The anti-MARK4L antibody stains the endogenous MARK4L protein (lower band) and the fusion protein (upper band), whose higher molecular weight is due to the Xpress tag and the histidine tail. The membrane was cut (black lines) after the blocking step and incubated with the appropriate antibodies. NT, non-transfected HEK293T cells; T, transfected HEK293T cells; M, molecular weight ladders $(\mathrm{kDa})$.

for 24 hours prior to protein extraction. By performing immunoblotting experiments on proteins from the transfected HEK293T cells, we determined that both the anti-Xpress ${ }^{\mathrm{TM}}$ and the GenScript anti-MARK4L antibodies recognized the over-expressed MARK4L protein (Suppl. Fig. 1).

\section{Abcam anti-MARK4S antibody validation}

Lysates (containing $1 \mathrm{mg}$ of proteins) from a representative glioma cell line and a tissue sample were subjected to direct immunoprecipitation. PureProteome ${ }^{\text {TM }}$ Protein G Magnetic Beads (100 $\mu$ l; Millipore) were incubated, following the manufacturer's instruction, with $10 \mu \mathrm{g}$ of anti-MARK4S antibody for 1 hour at RT with agitation. The lysate was then added to the immobilized antibody and incubated at $4{ }^{\circ} \mathrm{C} \mathrm{ON}$ with continuous mixing. After five washes in $0.5 \mathrm{ml}$ PBS containing $0.5 \%$ Tween 20 , the immunoprecipitated proteins were eluted in non-reducing SDS loading buffer (Cell Signaling Technology) by denaturing at $90^{\circ} \mathrm{C}$ for $10 \mathrm{~min}$ and subjected to SDS-PAGE, together with the corresponding whole cell lysates, as described [19].

Following electrophoresis, gels underwent both the immunoblotting procedure, described above, and mass-compatible silver staining.

For mass spectrometry identification, each band positively detected by immunoblotting analysis was excised, destained with $50 \%$ acetonitrile in $0.1 \mathrm{M}$ ammonium bicarbonate $\left(40 \mathrm{~min}\right.$ at $\left.25^{\circ} \mathrm{C}\right)$, dried in a Speed Vac, soaked with $0.1 \mathrm{M}$ ammonium bicarbonate, reduced, derivatised with 2-iodoacetamide and digested $\mathrm{ON}$ at $37^{\circ} \mathrm{C}$ with sequencing-grade trypsin (Roche, Monza, Italy). The in-gel tryptic digest was extracted with $50 \%$ acetonitrile in $0.1 \%$ trifluoroacetic acid (TFA). Digested aliquots were removed and subjected to a desalting/concentration step on a $\mu$ ZipTipC18 (Millipore) using $40 \% \mathrm{CH}_{3} \mathrm{CN}$ in $0.1 \%$ TFA as the eluent before LC-ESI-MS/MS analysis using a Dionex UltiMate 3000 HPLC System (Dionex S.p.A, San Donato Milanese, Italy) with a Hypersil Gold column $(150 \mathrm{~mm}$, internal diameter of $180 \mu \mathrm{m}$ filled with $3 \mu \mathrm{m}$ Reprosil-Pur C18-AQ resin - Dr. Maisch $\mathrm{GmbH}$, Ammerbuch-Entringen, Germany). The gradient consisted of 5-15\% acetonitrile in $0.1 \%$ formic acid for $10 \mathrm{~min}, 15-40 \%$ acetonitrile in $0.1 \%$ formic acid for $52 \mathrm{~min}$ and $40-95 \%$ acetonitrile in $0.1 \%$ formic for $68 \mathrm{~min}$ at a flow rate of $1.2 \mu \mathrm{l} / \mathrm{min}$. The eluate was electrosprayed into an LTQ Orbitrap Velos (Thermo Fisher Scientific, Bremen, Germany) through a Proxeon nanoelectrospray ion source. The LTQ Orbitrap Velos was operated in a CID top 5 mode. The resolution was $60.000(\mathrm{~m} / \mathrm{z} 400)$ for the Orbitrap, whereas fragment spectra were read out at low resolution in the LTQ. Ion trap and Orbitrap maximal injection times were set to $50 \mathrm{~ms}$ and $1000 \mathrm{~ms}$, respectively. The ion target values were 5.000 for the ion trap and 1.000.000 for the Orbitrap. Raw files were processed using version 1.1 of Protein Discoverer (Thermo Fisher Scientific). For protein identification, the SEQUEST program was used to search the NCBI Protein Data Bank with carbamidomethylation set as a fixed modification and oxidation (Met), phosphorylation (Ser, Thr and Tyr) and deamidation (Asn and Gln) set as variable modifications. Initial peptide mass tolerance was set to $10 \mathrm{ppm}$ and fragment mass tolerance was set to $0.8 \mathrm{Da}$. Two missed cleavages were allowed. Peptide quality scores were derived by processing against decoy shuffled databases.

Supplementary Figure 2 shows the mass spectrometry results from MI-4 whole cell lysate and reports the 


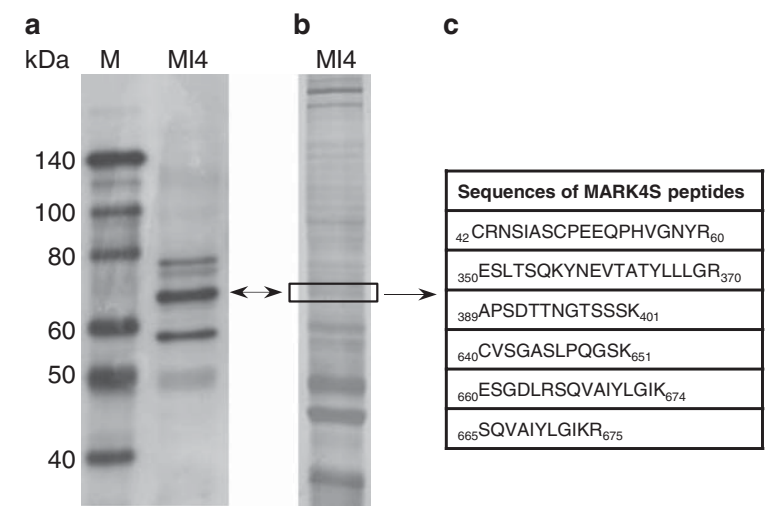

Supplementary Figure 2. Mass spectrometric identification of the band corresponding to MARK4S protein in MI-4 whole cell lysate. (A) Arrows indicate the band, detected by the anti-MARK4S antibody from Abcam, corresponding to MARK4S protein. (B) The matching silver-stained band was excised and analysed by mass spectrometry. (C) Sequences of MARK4S peptides found in the indicated band; the first three sequences are shared by both MARK4 isoforms (amino acids 1-625), whereas the last three are specific to the $\mathrm{S}$ isoform (amino acids 626-688). M, molecular weight ladders $(\mathrm{kDa})$.

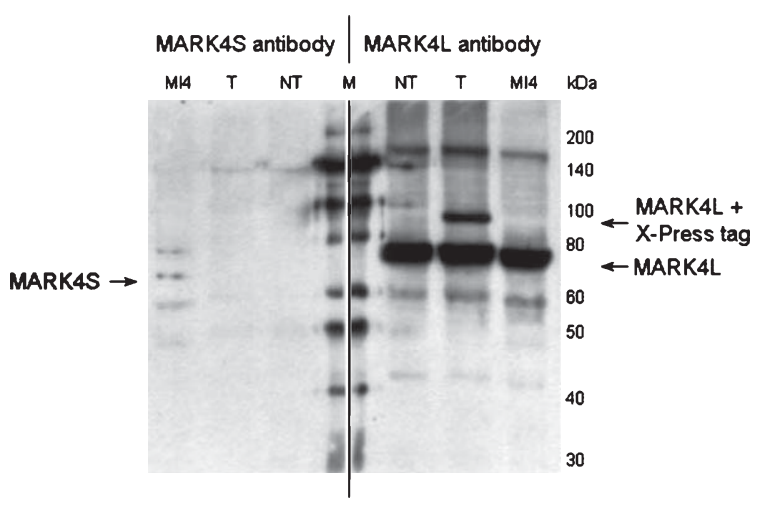

Supplementary Figure 3. The anti-MARK4S antibody does not recognize the over-expressed MARK4L protein. HEK293T cells were transfected with plasmid DNA encoding the fusion protein MARK4L + Xpress tag (lane T). The anti-MARK4L antibody (right) stains the endogenous MARK4L protein (lower band) and the over-expressed fusion protein (upper band). Signals from the antiMARK4S antibody (left) are present only in the MI-4 lane, whereas in HEK293T cells, there is no evidence of MARK4S expression. Significantly, the anti-MARK4S antibody does not stain the overexpressed MARK4L protein in transfected HEK293T cells. The membrane was cut (black line) after the blocking step and incubated with the appropriate antibodies. MI-4, glioblastoma cell line; T, transfected HEK293T cells; NT, non-transfected HEK293T cells; $\mathrm{M}$, molecular weight ladders ( $\mathrm{kDa})$. sequences of the peptides that allowed the unequivocal identification of the band indicated by the arrow as the MARK4S isoform. Data were also confirmed on immunoprecipitated samples (not shown).

In addition, we verified that the anti-MARK4S antibody did not recognize the L protein (Supplementary Figure 3).

\section{References}

[1] S. Guo and K.J. Kemphues, Par-1, a gene required for establishing polarity in C. elegans embryos, encodes a putative Ser/Thr kinase that is asymmetrically distributed, Cell $\mathbf{8 1}$ (1995), 611-620.

[2] J.M. Shulman, R. Benton and D. St Johnston, The Drosophila homolog of C. elegans PAR-1 organizes the oocyte cytoskeleton and directs oskar mRNA localization to the posterior pole, Cell 101 (2000), 377-388.

[3] G. Drewes, A. Ebneth, U. Preuss, E.M. Mandelkow and E. Mandelkow, MARK, a novel family of protein kinases that phosphorylate microtubule-associated proteins and trigger microtubule disruption, Cell 89 (1997), 297-308.

[4] B. Trinczek, M. Brajenovic, A. Ebneth and G. Drewes, MARK4 is a novel Microtubule-associated Proteins/Microtubule Affinity-regulating Kinase that binds to the cellular microtubule network and to centrosomes, J Biol Chem 279 (2004), 5915-5923.

[5] W. Biernat, Y. Tohma, Y. Yonekawa, P. Kleihues and H. Ohgaki, Alterations of cell cycle regulatory genes in primary (de novo) and secondary glioblastomas, Acta Neuropathol 94 (1997), 303-309.

[6] J.P. Tassan and X. Le Goff, An overview of the KIN1/PAR1/MARK kinase family, Biol Cell 96 (2004), 193-199.

[7] M. Elbert, G. Rossi and P. Brennwald, The yeast Par-1 homologs Kin1 and Kin2 show genetic and physical interactions with components of the exocytic machinery, Mol Biol Cell 16 (2005), 532-549.

[8] O. Göransson, M. Deak, S. Wullschleger, N.A. Morrice, A.R. Prescott and D.R. Alessi, Regulation of the polarity kinases PAR-1/MARK by 14-3-3 interaction and phosphorylation, $J$ Cell Sc 119 (2006), 4059-4070.

[9] G. Manning, D.B. Whyte, R. Martinez, T. Hunter and S. Sudarsanam, The protein kinase complement of the human genome, Science 298 (2002), 1912-1934.

[10] A. Marx, C. Nugoor, S. Panneerselvam and E. Mandelkow, Structure and function of polarity-inducing kinase family MARK/Par-1 within the branch of AMPK/Snf1-related kinases, FASEB J 24 (2010), 1637-1648.

[11] T. Kato, S. Satoh, H. Okabe, O. Kitahara, K. Ono, C. Kihara, T. Tanaka, T. Tsunoda, Y. Yamaoka, Y. Nakamura and Y. Furukawa, Isolation of a novel human gene, MARKL1, homologous to MARK3 and its involvement in hepatocellular carcinogenesis, Neoplasia 3 (2001), 4-9.

[12] R.F. Moroni, S. De Biasi, P. Colapietro, L. Larizza and A. Beghini, Distinct expression pattern of microtubule-associated protein/microtubule affinity-regulating kinase 4 in differentiated neurons, Neuroscience 143 (2006), 83-94. 
[13] A. Schneider, A. Laage, O. von Ahsen, A. Fischer, M. Rossner, S. Scheek, S. Grünewald, R. Kuner, D. Weber, C. Krüger, B. Klaussner, B. Götz, H. Hiemisch, D. Newrzella, A. MartinVillalba, A. Bach and M. Schwaninger, Identification of regulated genes during permanent focal cerebral ischemia: characterization of the protein kinase 9b5/MARKL1/MARK4, J Neurochem 88 (2004), 1114-1126.

[14] A. Beghini, I. Magnani, G. Roversi, T. Piepoli, S. Di Terlizzi, R.F. Moroni, B. Pollo, A.M. Fuhrman Conti, J.K. Cowell, G. Finocchiaro and L. Larizza, The neural progenitor-restricted isoform of the MARK4 gene in 19q13.2 is upregulated in human gliomas and overexpressed in a subset of glioblastoma cell lines, Oncogene 22 (2003), 2581-2591.

[15] D.W. Parsons, T.L. Wang, Y. Samuels, A. Bardelli, J.M. Cummins, L. DeLong, N. Silliman, J. Ptak, S. Szabo, J.K. Willson, S. Markowitz, K.W. Kinzler, B. Vogelstein, C. Lengauer and V.E. Velculescu, Colorectal cancer: Mutations in a signalling pathway, Nature 436 (2005), 792.

[16] S. Yamashita, Y. Tsujino, K. Moriguchi, M. Tatematsu and T. Ushijima, Chemical genomic screening for methylationsilenced genes in gastric cancer cell lines using 5-aza2 'deoxycytidine treatment and oligonucleotide microarray, Cancer Sci 97 (2006), 64-71.

[17] W. Sun, K. Zhang, X. Zhang, W. Lei, T. Xiao, J. Ma, S. Guo, S. Shao, H. Zhang, Y. Liu, J. Yuan and Z. Hu, Identification of differentially expressed genes in human lung squamous cell carcinoma using suppression subtractive hybridization, Cancer lett 212 (2004), 83-93.

[18] G. Roversi, R. Pfundt, R.F. Moroni, I. Magnani, S. van Reijmersdal, B. Pollo, H. Straatman, L. Larizza and E.F. Schoenmakers, Identification of novel genomic markers related to progression to glioblastoma through genomic profiling of 25 primary glioma cell lines, Oncogene 25 (2006), 1571-1583.

[19] I. Magnani, C. Novielli, M. Bellini, G. Roversi, L. Bello and L. Larizza, Multiple localization of endogenous MARK4L protein in human glioma, Cell oncol 31 (2009), 357-370.

[20] I. Magnani, S. Guerneri, B. Pollo, N. Cirenei, B.M. Colombo, G. Broggi, C. Galli, O. Bugiani, S. DiDonato, G. Finocchiaro and A.M. Fuhrman Conti, Increasing complexity of the karyotype in 50 human gliomas, Cancer Genet Cytogenet $\mathbf{7 5}$ (1994), 77-89.

[21] P. Perego, A. Boiardi, N. Carenini, M. De Cesare, E. Dolfini, R. Giardini, I. Magnani, S. Martignone, A. Silvani, C. Soranzo and F. Zunino, Characterization of an established human, malignant, glioblastoma cell line (GBM) and its response to conventional drugs, J Cancer Res Clin Oncol 120 (1994), 585-592.

[22] R. Galli, E. Binda, U. Orfanelli, B. Cipelletti, A. Gritti, S. De Vitis, R. Fiocco, C. Foroni, F. Dimeco and A. Vescovi, Isolation and characterization of tumorigenic, stem-like neural precursors from human glioblastoma, Cancer Res 64 (2004), 7011-7021.

[23] C. Foroni, R. Galli, B. Cipelletti, A. Caumo, S. Alberti, R. Fiocco and A. Vescovi, Resilience to transformation and inherent genetic and functional stability of adult neural stem cells ex vivo, Cancer Res 67 (2007), 3725-3733.

[24] K.J. Livak and T.D. Schmittgen, Analysis of relative gene expression data using real-time quantitative PCR and the $2^{-\Delta \Delta \mathrm{C}}$ T method, Methods 25 (2001), 402-408.
[25] J. Vandesompele, K. De Preter, F. Pattyn, B. Poppe, N. Van Roy, A. De Paepe and F. Speleman, Accurate normalization of real-time quantitative RT-PCR data by geometric averaging of multiple internal control genes, Genome Biol 3 (2002), 0034.1-0034.11.

[26] D.N. Louis, H. Ohgaki, O.D. Wiestler, W.K. Cavenee, P.C. Burger, A. Jouvet, B.W. Scheithauer and P. Kleihues, The 2007 WHO classification of tumours of the central nervous system, Acta Neuropathol 114 (2007), 97-109.

[27] Cancer Genome Atlas Research Network, Comprehensive genomic characterization defines human glioblastoma genes and core pathways, Nature 455 (2008), 1061-1068.

[28] S.C. Chauhan, N. Vinayek, D.M. Maher, M.C. Bell, K.A. Dunham, M.D. Koch, Y. Lio and M. Jaggi, Combined staining of TAG-72, MUC1 and CA125 improves labelling sensitivity in ovarian cancer: Antigens for multi-targeted antibody-guided therapy, J Histochem Cytochem 55 (2007), 867-875.

[29] J. Lee, S. Kotliarova, Y. Kotliarov, A. Li, Q. Su, N.M. Donin, S. Pastorino, B.W. Purow, N. Christopher, W. Zhang, J.K. Park and H.A. Fine, Tumor stem cells derived from glioblastomas cultured in bFGF and EGF more closely mirror the phenotype and genotype of primary tumors than do serum-cultured cell lines, Cancer Cell 9 (2006), 391-403.

[30] C. Greenman, P. Stephens, R. Smith, G.L. Dalgliesh, C. Hunter, G. Bignell, H. Davies, J. Teague, A. Butler, C. Stevens, S. Edkins, S. O'Meara, I. Vastrik, E.E. Schmidt, T. Avis, S. Barthorpe, G. Bhamra, G. Buck, B. Choudhury, J. Clements, J. Cole, E. Dicks, S. Forbes, K. Gray, K. Halliday, R. Harrison, K. Hills, J. Hinton, A. Jenkinson, D. Jones, et al., Patterns of somatic mutation in human cancer genomes, Nature $\mathbf{4 4 6}$ (2007), 153-158.

[31] M. Noble and J. Dietrich, The complex identity of brain tumors: Emerging concerns regarding origin, diversity and plasticity, Trends Neurosci 27 (2004), 148-154.

[32] A.L. Vescovi, R. Galli and B.A. Reynolds, Brain tumour stem cells, Nat Rev Cancer 6 (2006), 425-436.

[33] J.P. Venables, Unbalanced alternative splicing and its significance in cancer, Bioessays 28 (2006), 378-386.

[34] P.J. Grabowski and D.L. Black, Alternative RNA splicing in the nervous system, Prog Neurobiol 65 (2001), 289-308.

[35] F. Liu and C.X. Gong, Tau exon 10 alternative splicing and tauopathies, Mol Neurodegener 3 (2008), 8.

[36] H. Harris, A long view of fashions in cancer research, Bioessays 27 (2005), 833-888.

[37] A. Tacconelli, A.R. Farina, L. Cappabianca, A. Gulino and A.R. Mackay, TrkAIII. A novel hypoxia-regulated alternative TrkA splice variant of potential physiological and pathological importance, Cell Cycle 4 (2005), 8-9.

[38] A. Mohr, R.M. Zwacka, G. Jarmy, C. Büneker, H. Schrezenmeier, K. Döhner, C. Beltinger, M. Wiesneth, K.M. Debatin and K. Stahnke, Caspase-8L expression protects CD34+ hematopoietic progenitor cells and leukemic cells from CD95mediated apoptosis, Oncogene 24 (2005), 2421-2429.

[39] H. Mochizuki, T. Nishi, J.M. Bruner, P.S. Lee, V.A. Levin and H. Saya, Alternative splicing of neurofibromatosis type 1 gene transcript in malignant brain tumors: PCR analysis of frozensection mRNA, Mol Carcinog 6 (1992), 83-87.

[40] V. Vella, G. Pandini, L. Sciacca, R. Mineo, R. Vigneri, V. Pezzino and A. Belfiore, A novel autocrine loop involving 
IGF-II and the insulin receptor isoform-A stimulates growth of thyroid cancer, J Clin Endocrinol Metab 87 (2002), 245-254.

[41] S.K. Singh, I.D. Clarke, M. Terasaki, V.E. Bonn, C. Hawkins, J. Squire and P.B. Dirks, Identification of a cancer stem cell in human brain tumors, Cancer Res 63 (2003), 5821-5828.

[42] Q.B. Zhang, X.Y. Ji, Q. Huang, J. Dong, Y.D. Zhu and Q. Lan, Differentiation profile of brain tumor stem cells: A comparative study with neural stem cells, Cell Res 16 (2006), 909-915.

[43] L. López-Saavedra and L.A. Herrera, The role of alternative mRNA splicing in chromosome instability, Mutat Res $\mathbf{7 0 5}$ (2010), 246-225.

[44] K.M. Sze, Y.P. Ching, D.Y. Jin and I.O. Ng, Role of a novel splice variant of mitotic arrest deficient 1 (MAD1), MAD1beta, in mitotic checkpoint control in liver cancer, Cancer Res $\mathbf{6 8}$ (2008), 9194-9201.

[45] M. Yasen, H. Mizushima, K. Mogushi, G. Obulhasim, K. Miyaguchi, K. Inoue, I. Nakahara, T. Ohta, A. Aihara, S.
Tanaka, S. Arii and H. Tanaka, Expression of Aurora B and alternative variant forms in hepatocellular carcinoma and adjacent tissue, Cancer Sci 100 (2009), 472-480.

[46] A.R. Farina, A. Tacconelli, L. Cappabianca, G. Cea, S. Panella, A. Chioda, A. Romanelli, C. Pedone, A. Gulino and A.R. Mackay, The alternative TrkAIII splice variant targets the centrosome and promotes genetic instability, Mol Cell Biol 29 (2009), 4812-4830.

[47] R.S. Hames and A.M. Fry, Alternative splice variants of the human centrosome kinase Nek2 exhibit distinct patterns of expression in mitosis, Biochem J 361 (2002), 77-85.

[48] G. Drewes, A. Ebneth and E.M. Mandelkow, MAPs, MARKs and microtubule dynamics, Trends Biochem Sci 23 (1998), 307-311.

[49] M. Carmo-Fonseca, L. Mendes-Soares and I. Campos, To be or not to be in the nucleolus, Nat Cell Biol 2 (2000), E107-E112. 


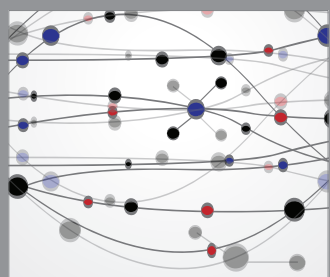

The Scientific World Journal
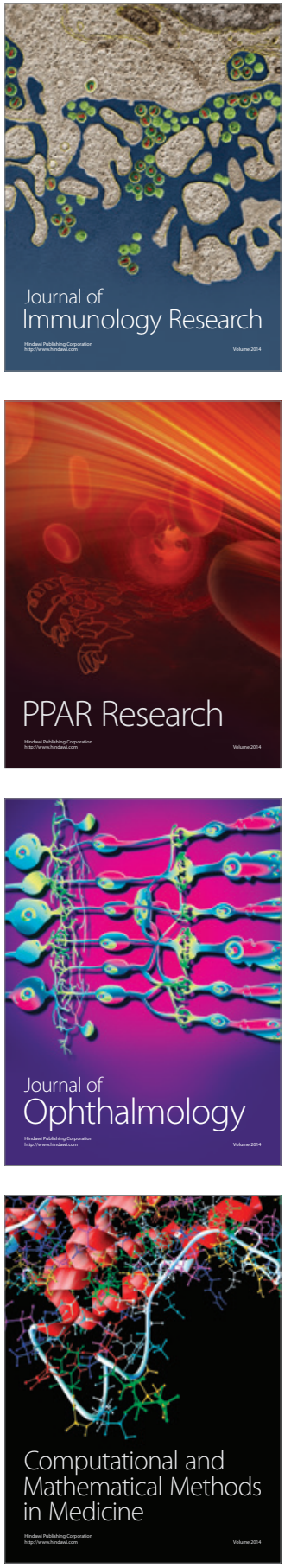

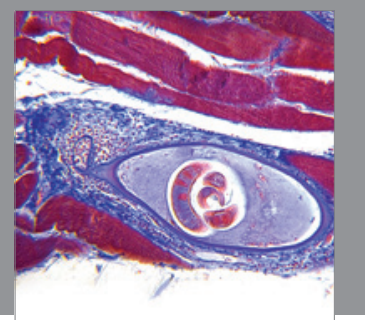

Gastroenterology

Research and Practice
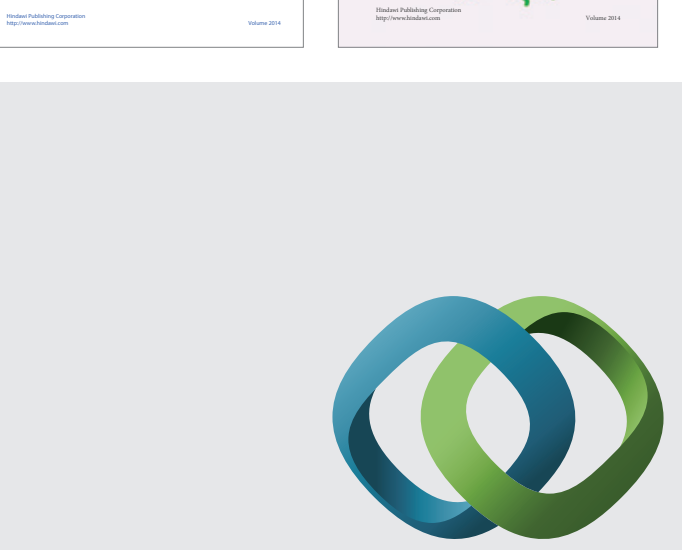

\section{Hindawi}

Submit your manuscripts at

http://www.hindawi.com
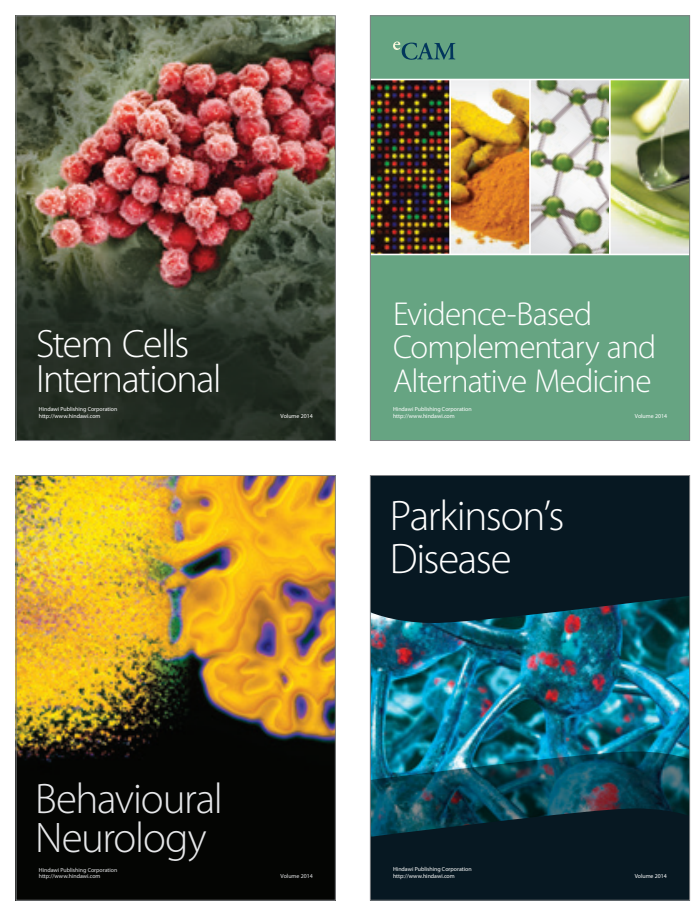

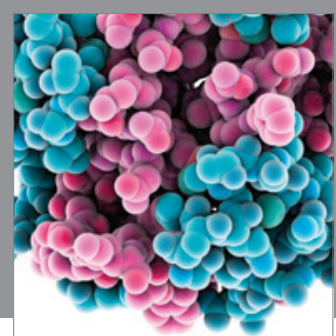

Journal of
Diabetes Research

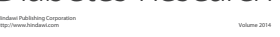

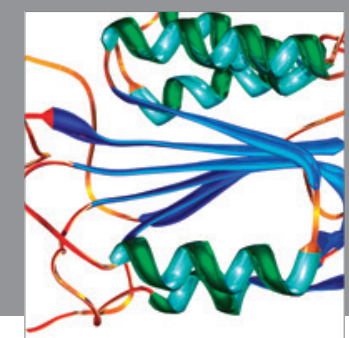

Disease Markers
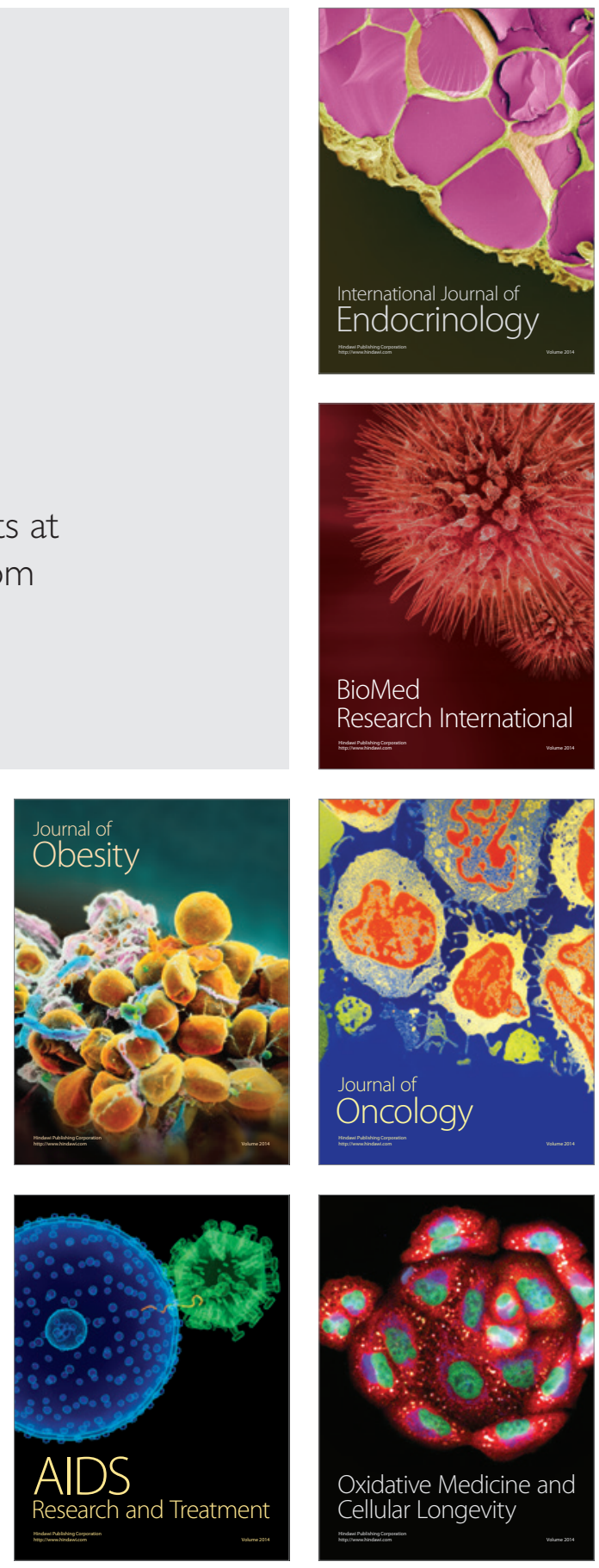